\title{
The Effects of Secretin, Pancreozymin, and Gastrin on Insulin and Glucagon Secretion in Anesthetized Dogs *
}

\author{
Roger H. Unger, $†$ Hermann Ketterer, John Dupré, and \\ Anna M. Eisentraut
}

(From the Department of Internal Medicine, The University of Texas Southwestern Medical School in Dallas, and the Veterans Administration Hospital, Dallas, Texas; and the Royal Victoria Hospital, Montreal, Canada)

\begin{abstract}
Summary. The effects upon islet hormone secretion of highly purified preparations of secretin and of pancreozymin-cholecystokinin and of a crude gastrin-containing extract of hog antrum have been studied in acutely operated dogs. All three preparations were shown to cause a striking increase in insulin concentration in the pancreaticoduodenal venous plasma after their rapid endoportal injection in anesthetized dogs. With each hormone preparation, the peak in insulin secretion occurred 1 minute after injection, and a rapid decline was observed immediately thereafter. Whereas secretin and gastrin failed to alter significantly the pancreaticoduodenal venous glucagon or arterial glucose concentration, pancreozymin caused a dramatic rise in pancreaticoduodenal venous glucagon concentration, which reached a peak 3 minutes after injection, and hyperglycemia was noted to occur soon thereafter. Endoportal infusion of secretin and pancreozymin for 20 minutes caused responses that were sustained but qualitatively identical to the responses noted after rapid injection of the hormones. The beta-cytotropic effect of secretin was abolished by the infusion of epinephrine.

These results could not be attributed to the small degree of contamination of the enteric hormone preparations with insulin or glucagon, and it would appear that secretin, pancreozymin, and probably gastrin have insulin-releasing activity and that pancreozymin has, in addition, glucagon-releasing activity.

The demonstration that these three hormones possess insulin-releasing activity suggests that there is in the gastrointestinal tract a chain of betacytotropic hormones from antrum to ileum that is capable of augmenting insulin secretion as required for disposal of substrate loads. It is suggested that the existence of this "entero-insular axis" prevents high substrate concentrations that would otherwise follow ingestion of large meals were the insular response entirely a function of arterial substrate concentration.
\end{abstract}

\section{Introduction}

The possibility that the secretory response of the islets of Langerhans to ingested food might

\footnotetext{
* Submitted for publication October 24, 1966; accepted December 30, 1966.

This study was supported by U. S. Public Health Service grant AM-02700-08, Syntex Research, Palo Alto, Calif., The Upjohn Co., Kalamazoo, Mich., and Pfizer Laboratories, New York, N. Y.

Presented in part at the meeting of the Central Society for Clinical Research, November 4, 1966, Chicago, Ill.
}

be influenced by humoral factors of the gastrointestinal tract was apparently first considered in 1906, when Moore, Edie, and Abram (1) administered an extract of duodenum to several diabetics in the hope of augmenting insulin secretion. Although the results of this therapeutic trial were not conclusive, the concept of an entero-insular hormonal axis continued to receive the attention

$\dagger$ Address requests for reprints to Dr. Roger H. Unger, Dept. of Internal Medicine, The University of Texas Southwestern Medical School, Dallas, Texas 75235. 
of investigators (2-7) until 1940, when a negative report by Loew, Gray, and Ivy (8) discredited the idea. In 1964 Dupré (9) revived interest in this question with a report that a crude secretincontaining extract of hog duodenal mucosa, prepared by the method of Crick, Harper, and Raper (10), accelerated the disappearance rate of intravenously administered glucose and increased insulin-like activity in man (11). Pfeiffer and associates (12) and McIntyre, Turner, and Holdsworth (13) noted in 1965 that the incubation of secretin with pieces of dog and rabbit pancreas enhanced the release of insulin. More recently, preliminary in vivo evidence of an insulinreleasing effect of secretin has been reported in dogs (14) and in humans (15).

The present study was designed to explore in dogs the effects of the enteric hormones secretin and pancreozymin-cholecystokinin and the antral hormone gastrin on insulin and glucagon secretion.

\section{Methods}

Mongrel dogs were anesthetized with Nembutal after an overnight fast, and a laparotomy was performed. An indwelling needle was placed in the pancreaticoduodenal vein in the direction of venous blood flow and its position stabilized. Obstruction to venous drainage was carefully avoided. A catheter was connected to the pancreaticoduodenal needle; catheters were also inserted in a femoral vein and a femoral artery. The patency of these vascular connections was maintained by local instillation of heparin. In addition a fourth catheter was inserted into a mesenteric vein, and normal saline was infused endoportally at a constant rate of $2 \mathrm{ml}$ per minute throughout each experiment.

Simultaneous samples of blood were obtained from the pancreaticoduodenal and femoral veins and from the femoral artery at frequent intervals before and after the rapid injection of the enteric hormone and before, during, and after its infusion. Mean arterial blood pressure was monitored continuously, and the hematocrit was determined at frequent intervals. All dogs included in the study were considered to have tolerated well both the surgery and the removal of blood.

Plasma glucose concentration was determined by the Hoffman ferricyanide method (16) with the Technicon Autoanalyzer. Insulin was measured by the method of Yalow and Berson (17). Plasma glucagon concentration was measured by the following modification of the previously described radioimmunoassay (18): Rabbit antiglucagon serum [diluted to $1: 321$ with $0.2 \mathrm{M}$ glycine buffer ( $\mathrm{pH} 8.9$ ) containing $0.25 \%$ human albumin and 1:100 nonimmune rabbit serum] and $0.05 \mathrm{ml}$ of either unknown undiluted plasma sample or a known crystal- line beef-pork glucagon standard ${ }^{1}$ were incubated at $4^{\circ} \mathrm{C}$ with $500 \mathrm{U}$ of $\mathrm{Trasylol}^{2}$ in $0.025 \mathrm{ml}$ of normal saline for 2 days. After 48 hours, $30 \mu \mu \mathrm{g}$ of glucagon ${ }^{131} \mathrm{I}$ in $0.05 \mathrm{ml}$ glycine albumin buffer was added and the incubation continued for an additional 20 hours at $4^{\circ} \mathrm{C}$. At the end of this time, $0.50 \mathrm{ml}$ of either $0.25 \%$ human albumin or undiluted nonimmune rabbit plasma containing bromophenol blue was added, and $0.2 \mathrm{ml}$ of this mixture was applied to the origin of a Whatman $3 \mathrm{MC}$ paper strip. After 2 hours of chromatography in a barbital buffer, the plasma proteins migrated $18 \mathrm{~cm}$ from the origin, and the strips were heat-dried, bisected, and counted in a well-type gamma scintillation counter. Results were corrected for nonspecific migration by the method of Yalow and Berson (17).

This assay has a high degree of precision; a recent analysis of replicate determinations of both known and unknown samples at all concentrations of glucagon revealed a standard error of $\pm 1.2 \%$. Recovery of crystalline glucagon is virtually quantitative. Although canine pancreatic glucagon appears to be immunologically similar to beef-pork glucagon (19), until canine standards are available the quantitative accuracy of assay results in absolute terms is uncertain. It seems probable, however, on physiologic grounds that the 0.4 to $2.0 \mathrm{~m} \mu \mathrm{g}$ per $\mathrm{ml}$ range of normal fasting dogs is close to the true glucagon level in the fasting state (20). Although it may still be necessary to regard the gluzagon assay as semiquantitative rather than quantitative, its precision and sensitivity make it possible to distinguish with $95 \%$ confidence differences in glucagon concentration $0.3 \mathrm{~m} \mu \mathrm{g}$ per $\mathrm{ml}$ or more. It may, therefore, be regarded as fully capable of measuring small changes in plasma glucagon levels in the relative sense of immunologic equivalence to beef-pork glucagon.

The use of the proteinase inhibitor Trasylol has been shown to eliminate almost completely the problem of incubation damage by human plasma to glucagon- ${ }^{131} \mathrm{I}$ (21). Although incubation damage poses more of a problem in the assay of human than canine plasma (21), Trasylol was added to the assay in this study be:ause of the possibility that variation in release of pancreatic proteolytic enzymes into the pancreatic vein might result from manipulation of the pancreas before the experiment. It has been found that it is not necessary to collect blood specimens in Trasylol-containing tubes, however (21).

Highly purified secretin, estimated to contain from 4,330 to $17,500 \mathrm{U}$ per $\mathrm{mg}$, and pancreozymin-cholecystokinin, said to contain $6,000 \mathrm{U}$ per $\mathrm{mg}$ (22), were provided $^{3}$ in vials containing 75 clinical $U$ of secretin and 300 Crick $U$ of pancreozymin. The contents of each vial were dissolved in $10 \mathrm{ml}$ normal saline, giving a con-

1 Kindly donated by Dr. W. R. Kirtley, Eli Lilly and Co., Indianapolis, Ind.

2 Trasylol-bay A 128-kindly supplied by FBA Pharmaceuticals, Inc., New York, N. Y.

${ }^{3}$ Kindly provided by Professor Erik Jorpes and Dr. Viktor Mutt of Karolinska Institutet, Stockholm, Sweden. 

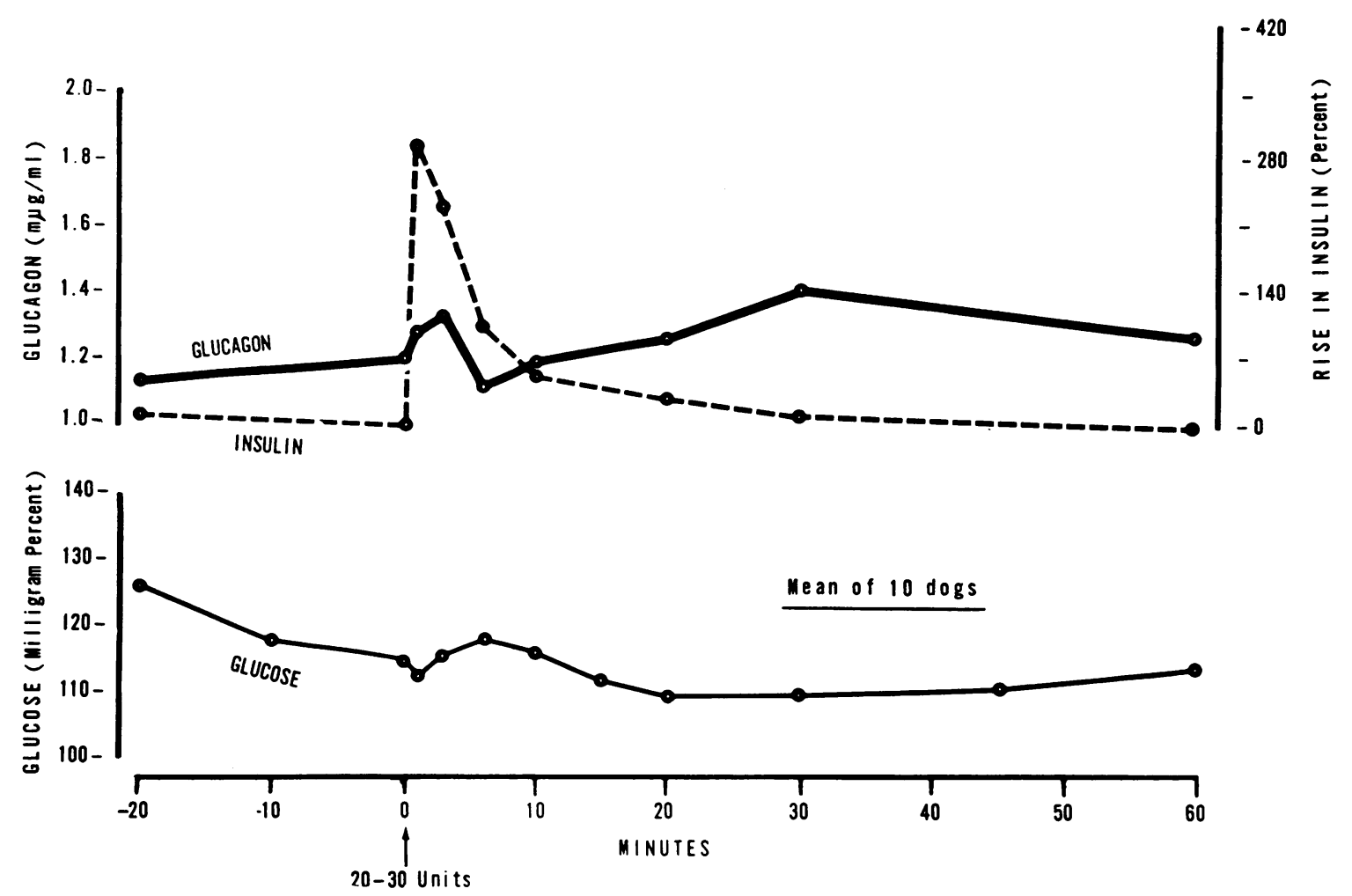

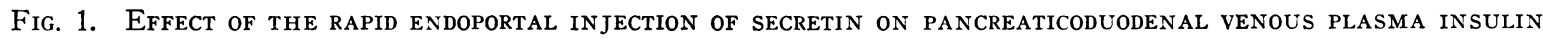
AND GLUCAGoN LEVELS AND ARTERIAL PLASMA GLUCOSE CONCENTRATION.

centration of $7.5 \mathrm{U}$ per $\mathrm{ml}$ of secretin and $30 \mathrm{U}$ per $\mathrm{ml}$ of pancreozymin. Secretin was administered through the mesenteric venous catheter by rapid injection of a dose of $1.5 \mathrm{U}$ per $\mathrm{kg}$ or by constant infusion at a rate of $10 \mathrm{U}$ per minute for 20 minutes; pancreozymin was administered by rapid injection in a dose of $100 \mathrm{U}$ or by constant infusion at a rate of $30 \mathrm{U}$ per minute for $20 \mathrm{~min}$ utes. Gastrin in the form of crude acetone powder,4 starting material for the purification of gastrin by the method of Tauber and Madison (23), was administered by rapid injection in a dose of 135 to $203 \mathrm{mU}$; gastrin II, ${ }^{5}$ prepared by the method of Gregory and Tracy (24), was administered in the same manner in a dose of 0.06 mg.

Every lot of each hormone was assayed for insulin and glucagon. All lots employed were free of insulin. Glucagon or glucagon-like immunoreactivity was from 0 to $3.7 \mathrm{~m} \mu \mathrm{g}$ per $\mathrm{U}$ in secretin, from 0.02 to $0.06 \mathrm{~m} \mu \mathrm{g}$ per $\mathrm{U}$ in pancreozymin, and $0.62 \mathrm{~m} \mu \mathrm{g}$ per $\mathrm{mU}$ in gastrin.

\section{Results}

Secretin injection. Immediately after the rapid endoportal injection of $1.5 \mathrm{U}$ per $\mathrm{kg}$ of secretin,

${ }^{4}$ Kindly donated by Dr. Stuart Tauber, Dallas, Texas.

5 Kindly donated by Dr. Morton Grossman, Los Angeles, Calif. a striking rise in pancreaticoduodenal venous insulin concentration was observed in each of 10 dogs (Figure 1). The mean insulin level for the group rose $294 \%$ from a preinjection value of $248 \mu \mathrm{U}$ per $\mathrm{ml}(\mathrm{SD} \pm 270)$ to $1,175 \mu \mathrm{U}$ per $\mathrm{ml}$ $(\mathrm{SD} \pm 830) 1$ minute after injection. The response was very brief, with a sharp decline occurring between 3 and 6 minutes after injection. Arterial insulin was measured in only one dog, 104, and reflected the changes in pancreatic venous insulin. There was no significant change in mean arterial glucose concentration for the group as a whole, although in some dogs a small rise was noted. However, such rises in plasma glucose were very small and followed the rise in insulin. Pancreatic venous glucagon concentration did not change significantly. The complete findings are recorded in Table $\mathrm{I}$.

Pancreozymin injection. The rapid injection of $100 \mathrm{U}$ of pancreozymin was also followed immediately by a sharp $484 \%$ rise in mean pancreaticoduodenal insulin concentration in each of 


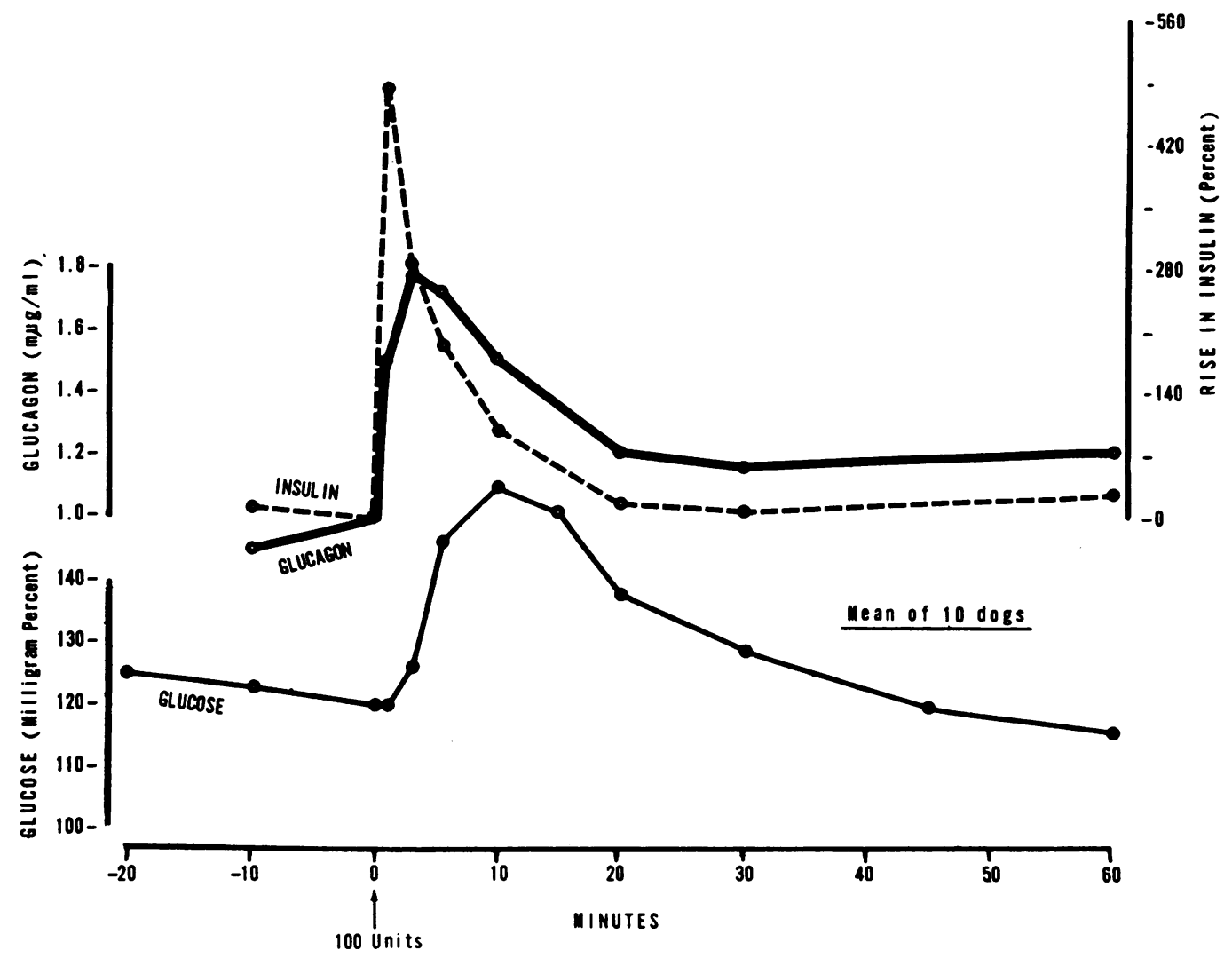

Fig. 2. EFFECT OF THE RAPID ENDOPORTAL INJECTION OF PANCREOZYMIN ON PANCREATICODUODENAL VENOUS

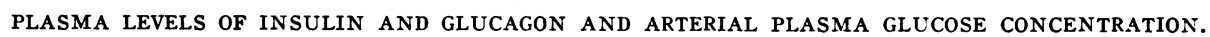

10 dogs. Mean insulin rose from $221 \mu \mathrm{U}$ per $\mathrm{ml}(\mathrm{SD} \pm 113)$ before injection to a peak of 1,291 $\mu \mathrm{U}$ per $\mathrm{ml}(\mathrm{SD} \pm 734) 1$ minute after injection (Figure 2). As with secretin, this rise was shortlived and declined rapidly between 1 and $10 \mathrm{~min}$ utes after injection. In contrast to the lack of a clear-cut effect of secretin upon glucagon concentration, however, the administration of pancreozymin was followed in 8 of the 10 dogs by a rapid rise in the pancreaticoduodenal venous glucagon concentration. The mean level rose from $1 \mathrm{~m} \mu \mathrm{g}$ per $\mathrm{ml}(\mathrm{SD} \pm 0.25)$ before the injection to a 3 -minute level of $1.78 \mathrm{~m} \mu \mathrm{g}$ per $\mathrm{ml}(\mathrm{SD} \pm 0.91)$, after which it gradually declined; the mean of all 10 peak values, irrespective of time, was $2.15 \mathrm{~m} \mu \mathrm{g}$ per $\mathrm{ml}(\mathrm{SD} \pm 0.73$ ), a rise of $1.15 \mathrm{~m} \mu \mathrm{g}$ per $\mathrm{ml}$. Plasma glucose concentration rose slowly from $120 \mathrm{mg}$ per $100 \mathrm{ml}(\mathrm{SD} \pm 10.3$ ) to a peak of 155 $\mathrm{mg}$ per $100 \mathrm{ml}(\mathrm{SD} \pm 25.8)$ at 10 minutes. The time of the rise in glucose concentration was far too late to be causally related to the rise in insulin.
The individual results of these experiments are recorded in Table II.

Gastrin injection. Rapid endoportal injection of a gastrin-containing extract of hog antrum in three dogs was followed by a rapid $385 \%$ rise in

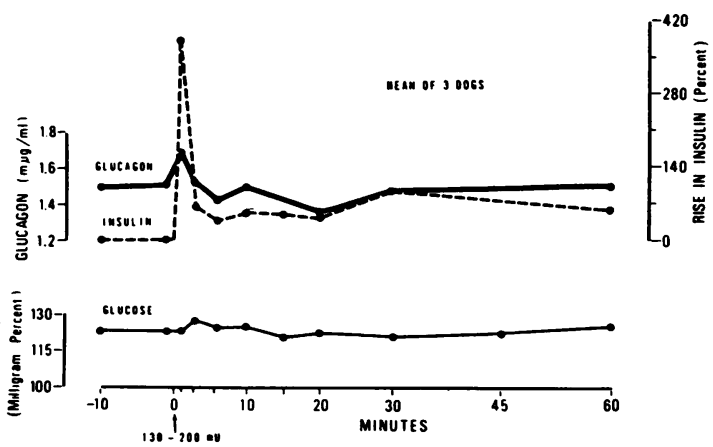

Fig. 3. EFFECT OF THE ENDOPORTAL INJECTION OF CRUDE GASTRIN UPON THE PANCREATICODUODENAL VENOUS PLASMA LEVELS OF INSULIN AND GLUCAGON AND THE ARTERIAL PLASMA GLUCOSE CONCENTRATION. 
TABLE I

Effect of endoportal injection of 20 to $30 U$ of secretin on arterial glucose $(A G)$, pancreatic venous insulin $(P V I)$, and pancreatic venous glucagon $(P V G)$

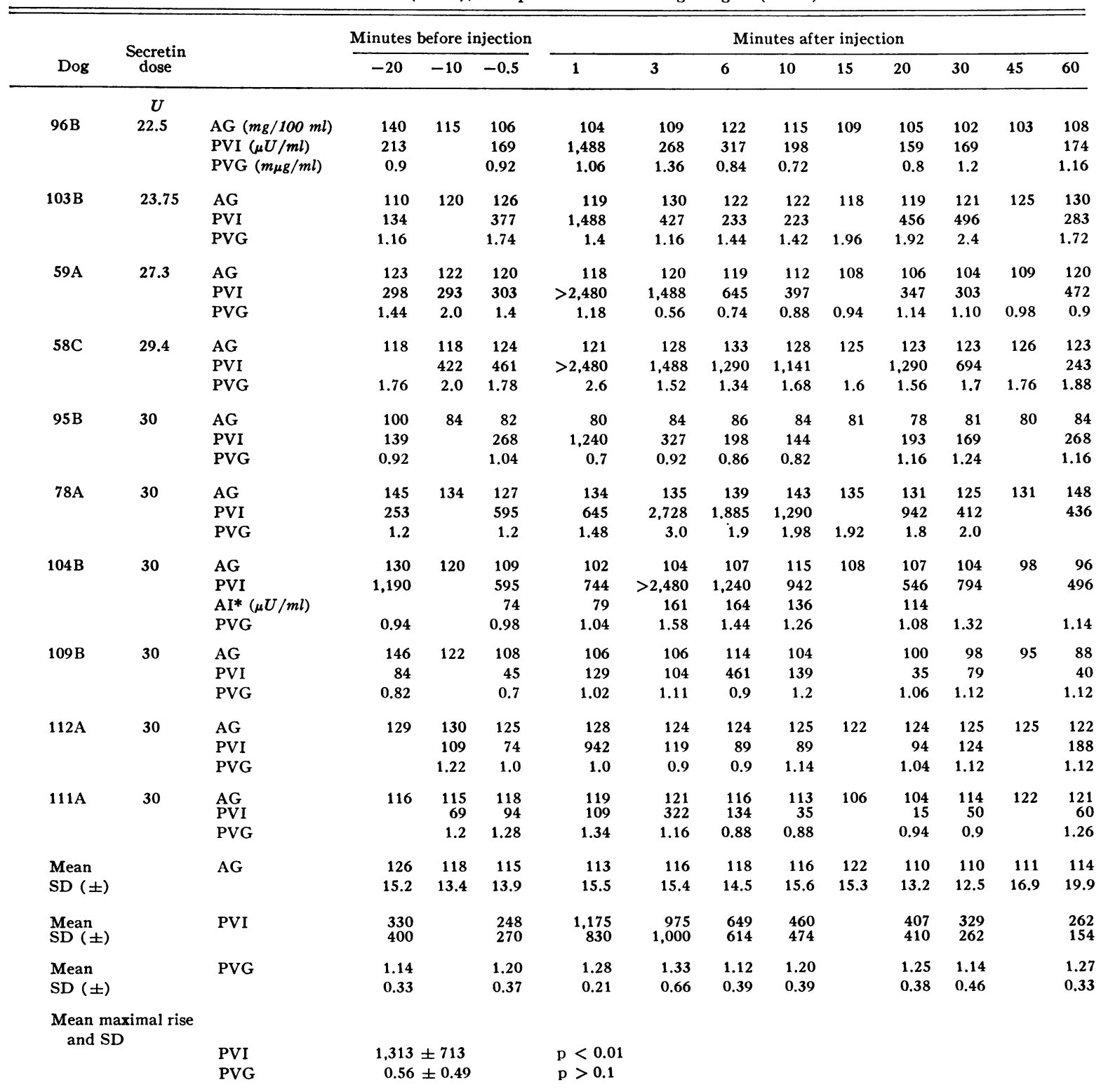

* Arterial insulin concentration.

the mean pancreaticoduodenal venous insulin concentration from a preinjection value of $193 \mu \mathrm{U}$ per $\mathrm{ml}(\mathrm{SD} \pm 123.3$ ) to a peak of $937 \mu \mathrm{U}$ per $\mathrm{ml}$ $(\mathrm{SD} \pm 661.4) 1$ minute after injection (Figure 3 ). Again a rapid decline occurred, with a return to the base-line value within 6 minutes. A 0.19 $\mathrm{m} \mu \mathrm{g}$ per $\mathrm{ml}$ rise in mean pancreaticoduodenal venous glucagon concentration was noted at $1 \mathrm{~min}-$ ute after injection in parallel with a $4 \mathrm{mg}$ per 100 $\mathrm{ml}$ rise in glucose concentration. The administration of $0.06 \mathrm{mg}$ of pure porcine gastrin II elicited the same type of insulin response; the pancreaticoduodenal insulin level rose more than tenfold, from 169 to $1,835 \mu \mathrm{U}$ per ml 3 minutes after the injection.

Glucagon content of injected hormone solutions 
TABLE II

Effect of endoportal injection of pancreozymin-cholecystokinin on $A G, P V I$, and $P V G$

\begin{tabular}{|c|c|c|c|c|c|c|c|c|c|c|c|c|c|c|}
\hline \multirow[b]{2}{*}{ Dog } & \multirow[b]{2}{*}{ Dose } & & \multicolumn{3}{|c|}{ Minutes before injection } & \multicolumn{9}{|c|}{ Minutes after injection } \\
\hline & & & -20 & -10 & -0.5 & 1 & 3 & 6 & 10 & 15 & 20 & 30 & 45 & 60 \\
\hline 95 & $\begin{array}{c}U \\
100\end{array}$ & $\begin{array}{l}\text { AG }(m g / 100 m l) \\
\text { PVI }(\mu U / m l) \\
\text { PVG }(m \mu g / m l)\end{array}$ & 100 & $\begin{array}{r}98 \\
263 \\
0.68\end{array}$ & $\begin{array}{r}94 \\
258 \\
0.8\end{array}$ & $\begin{array}{r}90 \\
1,438 \\
1.48\end{array}$ & $\begin{array}{r}104 \\
744 \\
2.0\end{array}$ & $\begin{array}{r}114 \\
794 \\
1.28\end{array}$ & $\begin{array}{r}132 \\
595 \\
1.0\end{array}$ & 120 & $\begin{array}{r}111 \\
243 \\
0.92\end{array}$ & $\begin{array}{r}100 \\
139 \\
0.92\end{array}$ & 84 & $\begin{array}{r}82 \\
268 \\
1.04\end{array}$ \\
\hline 96 & 100 & $\begin{array}{l}\text { AG } \\
\text { PVI } \\
\text { PVG }\end{array}$ & 121 & $\begin{array}{r}124 \\
124 \\
0.84\end{array}$ & $\begin{array}{r}121 \\
238 \\
1.02\end{array}$ & $\begin{array}{r}118 \\
>2,600 \\
1.82\end{array}$ & $\begin{array}{r}120 \\
843 \\
2.4\end{array}$ & $\begin{array}{r}161 \\
595 \\
1.68\end{array}$ & $\begin{array}{r}177 \\
397 \\
1.4\end{array}$ & 188 & \begin{tabular}{r|}
169 \\
238 \\
1.04
\end{tabular} & $\begin{array}{l}140 \\
213 \\
0.90\end{array}$ & 115 & $\begin{array}{l}106 \\
169 \\
0.92\end{array}$ \\
\hline 99 & 100 & $\begin{array}{l}\text { AG } \\
\text { PVI } \\
\text { PVG }\end{array}$ & 118 & $\begin{array}{r}121 \\
119 \\
0.68\end{array}$ & $\begin{array}{r}122 \\
114 \\
0.74\end{array}$ & $\begin{array}{r}122 \\
1,091 \\
1.17\end{array}$ & $\begin{array}{r}122 \\
451 \\
0.83\end{array}$ & $\begin{array}{l}131 \\
188 \\
0.8\end{array}$ & $\begin{array}{r}120 \\
119 \\
0.8\end{array}$ & 1.0 & $\begin{array}{r}109 \\
74 \\
0.88\end{array}$ & $\begin{array}{r}110 \\
109 \\
0.94\end{array}$ & 118 & $\begin{array}{r}122 \\
139 \\
0.96\end{array}$ \\
\hline 103 & 100 & $\begin{array}{l}\text { AG } \\
\text { PVI } \\
\text { PVG }\end{array}$ & 129 & $\begin{array}{r}122 \\
283 \\
0.72\end{array}$ & $\begin{array}{r}124 \\
298 \\
0.76\end{array}$ & $\begin{array}{r}123 \\
1,488 \\
0.88\end{array}$ & $\begin{array}{r}135 \\
893 \\
0.9\end{array}$ & $\begin{array}{r}138 \\
744 \\
0.94\end{array}$ & $\begin{array}{r}132 \\
188 \\
0.96\end{array}$ & 1.2 & $\begin{array}{r}113 \\
79 \\
1.0\end{array}$ & \begin{tabular}{r|}
110 \\
134 \\
1.16
\end{tabular} & 120 & $\begin{array}{r}126 \\
377 \\
1.74\end{array}$ \\
\hline $104 \mathrm{~A}$ & 100 & $\begin{array}{l}\text { AG } \\
\text { PVI } \\
\text { PVG }\end{array}$ & 131 & $\begin{array}{r}124 \\
293 \\
0.88\end{array}$ & $\begin{array}{r}129 \\
382 \\
0.96\end{array}$ & $\begin{array}{r}129 \\
1.091 \\
1.98\end{array}$ & $\begin{array}{r}137 \\
942 \\
1.54\end{array}$ & $\begin{array}{r}167 \\
744 \\
1.56\end{array}$ & $\begin{array}{r}180 \\
476 \\
1.28\end{array}$ & 1.26 & $\begin{array}{r}152 \\
427 \\
1.16\end{array}$ & $\begin{array}{r}145 \\
253 \\
1.2\end{array}$ & 134 & $\begin{array}{r}127 \\
595 \\
1.2\end{array}$ \\
\hline $108 \mathrm{~A}$ & 100 & $\begin{array}{l}\text { AG } \\
\text { PVI } \\
\text { PVG }\end{array}$ & 133 & $\begin{array}{r}131 \\
446 \\
1.0\end{array}$ & $\begin{array}{r}342 \\
0.9\end{array}$ & $\begin{array}{r}129 \\
794 \\
0.98\end{array}$ & $\begin{array}{r}131 \\
>2,480 \\
1.62\end{array}$ & $\begin{array}{r}136 \\
1,240 \\
2.2\end{array}$ & $\begin{array}{r}144 \\
942 \\
1.32\end{array}$ & 158 & $\begin{array}{r}139 \\
546 \\
1.0\end{array}$ & $\begin{array}{r}130 \\
794 \\
0.94\end{array}$ & 120 & $\begin{array}{l}109 \\
496 \\
0.98\end{array}$ \\
\hline $109 \mathrm{~A}$ & 100 & $\begin{array}{l}\text { AG } \\
\text { PVI } \\
\text { PVG }\end{array}$ & 132 & $\begin{array}{r}132 \\
30 \\
0.7\end{array}$ & $\begin{array}{r}119 \\
60 \\
0.88\end{array}$ & $\begin{array}{r}117 \\
>2,480 \\
1.96\end{array}$ & $\begin{array}{r}136 \\
233 \\
1.26\end{array}$ & $\begin{array}{r}178 \\
794 \\
1.66\end{array}$ & $\begin{array}{r}200 \\
432 \\
1.08\end{array}$ & 196 & $\begin{array}{r}155 \\
109 \\
0.94\end{array}$ & $\begin{array}{r}146 \\
84 \\
0.82\end{array}$ & 122 & $\begin{array}{r}108 \\
45 \\
0.7\end{array}$ \\
\hline $110 \mathrm{~B}$ & 100 & $\begin{array}{l}\text { AG } \\
\text { PVI } \\
\text { PVG }\end{array}$ & 142 & $\begin{array}{l}134 \\
382\end{array}$ & $\begin{array}{r}128 \\
268 \\
1.54\end{array}$ & $\begin{array}{r}127 \\
694 \\
1.94\end{array}$ & $\begin{array}{r}125 \\
1,290 \\
4.0\end{array}$ & $\begin{array}{r}153 \\
744 \\
4.0\end{array}$ & $\begin{array}{r}171 \\
844 \\
2.6\end{array}$ & 165 & $\begin{array}{r}160 \\
694 \\
2.2\end{array}$ & $\begin{array}{r}145 \\
456 \\
1.9\end{array}$ & 134 & $\begin{array}{r}134 \\
337 \\
1.94\end{array}$ \\
\hline 111 & 100 & $\begin{array}{l}\text { AG } \\
\text { PVI } \\
\text { PVG }\end{array}$ & $\begin{array}{r}114 \\
50 \\
0.9\end{array}$ & 122 & $\begin{array}{r}121 \\
60 \\
1.26\end{array}$ & $\begin{array}{r}122 \\
436 \\
1.43\end{array}$ & $\begin{array}{r}129 \\
322 \\
1.58\end{array}$ & $\begin{array}{r}145 \\
223 \\
1.48\end{array}$ & $\begin{array}{r}144 \\
144 \\
1.48\end{array}$ & 136 & $\begin{array}{r}130 \\
30 \\
1.12\end{array}$ & $\begin{array}{r}124 \\
60 \\
1.16\end{array}$ & 123 & $\begin{array}{r}122 \\
263 \\
1.34\end{array}$ \\
\hline 112B & 100 & $\begin{array}{l}\text { AG } \\
\text { PVI } \\
\text { PVG }\end{array}$ & $\begin{array}{r}125 \\
124 \\
1.12\end{array}$ & 125 & $\begin{array}{r}122 \\
188 \\
1.12\end{array}$ & $\begin{array}{r}125 \\
794 \\
1.38\end{array}$ & $\begin{array}{r}124 \\
223 \\
1.66\end{array}$ & $\begin{array}{r}138 \\
362 \\
1.56\end{array}$ & \begin{tabular}{r|}
147 \\
188 \\
3.2
\end{tabular} & 143 & $\begin{array}{l}140 \\
174 \\
1.8\end{array}$ & $\begin{array}{r}134 \\
114 \\
1.76\end{array}$ & 126 & $\begin{array}{r}126 \\
134 \\
1.4\end{array}$ \\
\hline $\begin{array}{l}\text { Mean } \\
\text { SD }\end{array}$ & & $\begin{array}{l}\text { AG } \\
\pm\end{array}$ & $\begin{array}{r}125 \\
11.9\end{array}$ & $\begin{array}{r}123 \\
10.0\end{array}$ & $\begin{array}{r}120 \\
10.3\end{array}$ & $\begin{array}{r}120 \\
11.4\end{array}$ & $\begin{array}{r}126 \\
9.9\end{array}$ & $\begin{array}{r}146 \\
18.9\end{array}$ & $\begin{array}{r}155 \\
25.8\end{array}$ & $\begin{array}{r}151 \\
28.3\end{array}$ & $\begin{array}{r}138 \\
21.6\end{array}$ & $\begin{array}{r}129 \\
16.5\end{array}$ & $\begin{array}{r}120 \\
14.0\end{array}$ & $\begin{array}{r}116 \\
15.2\end{array}$ \\
\hline $\begin{array}{l}\text { Mean } \\
\text { SD }\end{array}$ & & $\begin{array}{l}\text { PVI } \\
\pm\end{array}$ & & $\begin{array}{l}243 \\
141\end{array}$ & $\begin{array}{l}221 \\
113\end{array}$ & $\begin{array}{r}1,291 \\
734\end{array}$ & $\begin{array}{l}842 \\
674\end{array}$ & $\begin{array}{l}643 \\
316\end{array}$ & $\begin{array}{l}433 \\
303\end{array}$ & & $\begin{array}{l}261 \\
223\end{array}$ & $\begin{array}{l}245 \\
239\end{array}$ & & $\begin{array}{l}282 \\
173\end{array}$ \\
\hline $\begin{array}{l}\text { Mean } \\
\text { SD }\end{array}$ & & $\begin{array}{l}\text { PVG } \\
\pm\end{array}$ & & $\begin{array}{l}0.79 \\
0.12\end{array}$ & $\begin{array}{l}1.00 \\
0.25\end{array}$ & $\begin{array}{l}1.50 \\
0.41\end{array}$ & $\begin{array}{l}1.78 \\
0.91\end{array}$ & $\begin{array}{l}1.72 \\
0.89\end{array}$ & $\begin{array}{l}1.51 \\
0.77\end{array}$ & & $\begin{array}{l}1.21 \\
0.44\end{array}$ & $\begin{array}{l}1.17 \\
0.37\end{array}$ & & $\begin{array}{l}1.22 \\
0.39\end{array}$ \\
\hline \multicolumn{14}{|c|}{$\begin{array}{l}\text { Mean maximal rise } \\
\text { and SD }\end{array}$} & \\
\hline
\end{tabular}

and its effect on the results. Glucagon has been shown to have potent insulin-releasing activity in man (25-27) and in dogs (20), even in small doses of less than $100 \mathrm{~m} \mu \mathrm{g}$; since glucagon-like immunoreactivity is present in the gut $(28,19$, 29), its presence as a contaminant in preparation of gut hormones would not be unexpected and might play a role in the rise in insulin excretion observed. For this reason, in each experiment a sample of the hormone solution was removed from the syringe before its injection and its glucagon concentration measured. Secretin solutions contained from 0 to $3.7 \mathrm{~m} \mu \mathrm{g}$ per $\mathrm{U}$, pancreozymin from 0.02 to $0.06 \mathrm{~m} \mu \mathrm{g}$ per $\mathrm{U}$, and gastrin 0.62 $\mathrm{m} \mu \mathrm{g}$ per $\mathrm{U}$. These quantities are known to be insufficient to cause a rise in insulin of the magnitude observed (20), although potentiation by glucagon of the effect of another hormone is a possibility. The large rise in glucagon concentration observed after the injection of pancreozymin cannot be explained by its glucagon content; however, the small rise in pancreatic venous glucagon ob- 
TABLE III

Effects of endoportal injection of crude gastrin on $A G, P V I$, and $P V G$, and of purified porcine gastrin II on $A G$ and $P V G$

\begin{tabular}{|c|c|c|c|c|c|c|c|c|c|c|c|c|c|}
\hline \multirow[b]{2}{*}{ Dog } & \multirow{2}{*}{$\begin{array}{c}\text { Gastrin } \\
\text { dose }\end{array}$} & & \multicolumn{2}{|c|}{$\begin{array}{c}\text { Minutes before } \\
\text { injection }\end{array}$} & \multicolumn{9}{|c|}{ Minutes after injection } \\
\hline & & & -10 & $0-1$ & 1 & 3 & 6 & 10 & 15 & 20 & 30 & 45 & 60 \\
\hline & $m U$ & A. crude gastrin & & & & & & & & & & & \\
\hline 125 & 203 & $\begin{array}{l}\mathrm{AG}(m g / 100 m l) \\
\mathrm{PVI}(\mu U / m l) \\
\mathrm{PVG}(m \mu g / m l)\end{array}$ & $\begin{array}{r}113 \\
471 \\
1.48\end{array}$ & $\begin{array}{r}115 \\
169 \\
1.34\end{array}$ & $\begin{array}{r}115 \\
1,640 \\
1.40\end{array}$ & $\begin{array}{r}120 \\
486 \\
1.30\end{array}$ & $\begin{array}{r}119 \\
392 \\
1.32\end{array}$ & $\begin{array}{r}120 \\
312 \\
1.30\end{array}$ & 112 & $\begin{array}{r}112 \\
327 \\
1.26\end{array}$ & $\begin{array}{r}111 \\
416 \\
1.26\end{array}$ & 112 & $\begin{array}{r}114 \\
288 \\
1.44\end{array}$ \\
\hline 126 & 135 & $\begin{array}{l}\text { AG } \\
\text { PVI } \\
\text { PVG }\end{array}$ & $\begin{array}{r}129 \\
442 \\
1.50\end{array}$ & $\begin{array}{r}123 \\
327 \\
1.44\end{array}$ & $\begin{array}{r}125 \\
844 \\
1.84\end{array}$ & $\begin{array}{r}129 \\
342 \\
1.54\end{array}$ & $\begin{array}{r}123 \\
332 \\
1.46\end{array}$ & $\begin{array}{r}126 \\
482 \\
1.58\end{array}$ & 127 & $\begin{array}{r}130 \\
432 \\
1.44\end{array}$ & $\begin{array}{r}132 \\
644 \\
1.48\end{array}$ & 123 & $\begin{array}{r}135 \\
546 \\
1.46\end{array}$ \\
\hline 127 & 180 & $\begin{array}{l}\text { AG } \\
\text { PVI } \\
\text { PVG }\end{array}$ & $\begin{array}{r}127 \\
74 \\
1.48\end{array}$ & $\begin{array}{r}132 \\
84 \\
1.72\end{array}$ & $\begin{array}{r}130 \\
327 \\
1.84\end{array}$ & $\begin{array}{l}133 \\
109 \\
1.72\end{array}$ & $\begin{array}{r}129 \\
74 \\
1.48\end{array}$ & $\begin{array}{r}129 \\
94 \\
1.60\end{array}$ & 122 & $\begin{array}{r}123 \\
79 \\
1.36\end{array}$ & $\begin{array}{r}120 \\
89 \\
1.68\end{array}$ & 132 & $\begin{array}{r}125 \\
94 \\
1.58\end{array}$ \\
\hline Mean & & $\begin{array}{l}\text { AG } \\
\text { PVI } \\
\text { PVG }\end{array}$ & $\begin{array}{r}123 \\
329 \\
1.49\end{array}$ & $\begin{array}{r}123 \\
193 \\
1.50\end{array}$ & $\begin{array}{r}123 \\
937 \\
1.69\end{array}$ & $\begin{array}{r}127 \\
312 \\
1.52\end{array}$ & $\begin{array}{r}124 \\
266 \\
1.42\end{array}$ & $\begin{array}{r}125 \\
296 \\
1.49\end{array}$ & 120 & $\begin{array}{r}122 \\
279 \\
1.35\end{array}$ & $\begin{array}{r}121 \\
383 \\
1.47\end{array}$ & 122 & $\begin{array}{r}125 \\
309 \\
1.49\end{array}$ \\
\hline \multicolumn{14}{|c|}{ B. purified porcine gastrin II } \\
\hline 183 & $\begin{array}{c}m g \\
0.06\end{array}$ & $\begin{array}{l}\text { AG } \\
\text { PVI }\end{array}$ & $\begin{array}{l}127 \\
129\end{array}$ & $\begin{array}{l}132 \\
169\end{array}$ & $\begin{array}{r}130 \\
1,835\end{array}$ & $\begin{array}{l}135 \\
169\end{array}$ & $\begin{array}{l}142 \\
357\end{array}$ & $\begin{array}{l}131 \\
154\end{array}$ & $\begin{array}{r}123 \\
45\end{array}$ & $\begin{array}{r}117 \\
60\end{array}$ & $\begin{array}{r}115 \\
90\end{array}$ & & \\
\hline
\end{tabular}

served after gastrin injection may well be the consequence of its glucagon contaminant.

It seemed barely possible that the rise in pancreaticoduodenal venous glucagon concentration observed after pancreozymin administration was a consequence of reflux of the glucagon contaminant from the portal vein into the indwelling pancreatic venous needle. For this reason, six pancreozymin experiments were performed with a catheter inserted into the pancreatic vein in a retrograde direction and tied in place; thus, the entire pancreaticoduodenal vein effluent was collected, making reflux from the portal vein impossible. In these experiments, the rise in mean glucagon concentration after the injection of pancreozymin was substantially greater than in the other experiments, with a peak at 3 minutes of 3.19 $\mathrm{m} \mu \mathrm{g}$ per $\mathrm{ml}$ as compared with $1.78 \mathrm{~m} \mu \mathrm{g}$ per $\mathrm{ml}$ (Table IV).

These results not only exclude reflux of glucagon from the portal vein as a cause of the rise in glucagon concentration, but they point to the pancreas rather than to the gut as the principal source of the pancreozymin-induced rise in glucagon concentration.

Effects of inactive secretin and other polypeptide hormones. Inasmuch as each of the four hor- mones examined thus far, secretin, pancreozymin, gastrin, and glucagon, have been shown to elicit a very prompt and short-lived rise in pancreaticoduodenal venous insulin concentration when injected endoportally in anesthetized dogs, it seemed possible that this might be a nonspecific response to the rapid injection of a polypeptide. For this reason, the effects on insulin secretion of several other polypeptide hormones not of gastrointestinal origin and of a preparation of secretin that had been shown to have lost its secretagogue activity (22) were studied.

The administration via a peripheral vein of large doses of three other polypeptide hormones, ovine growth hormone, vasopressin, and ACTH, failed to elicit the same pattern of insulin response as observed after injection of the gastrointestinal hormones. After $20 \mathrm{U}$ of vasopressin, insulin secretion seemed to decline at first and then rise in parallel with the blood glucose level (Figure 4). One $\mathrm{mg}$ ACTH seemed to induce a small early rise in insulin concentration lasting 3 minutes and an apparent decline in glucagon concentration (Figure 4). In a 2-mg dose, ovine growth hormone had no immediate effect on insulin concentration, but a late rise in plasma glucose and insulin concentration was noted (Figure 4). Al- 
TABLE IV

Effect of endoportal injection of cholecystokinin-pancreozymin on $A G$ or venous glucose (VG), $P V I$, and $P V G$ during retrograde catheterization of the pancreatic vein

\begin{tabular}{|c|c|c|c|c|c|c|c|c|c|}
\hline \multirow[b]{2}{*}{ Dog } & \multirow[b]{2}{*}{ Dose } & & \multicolumn{3}{|c|}{ Minutes before injection } & \multicolumn{4}{|c|}{ Minutes after injection } \\
\hline & & & -3 & -2 & -1 & 1 & 3 & 6 & 10 \\
\hline PZ3 & $\begin{array}{c}U \\
100\end{array}$ & $\begin{array}{l}\text { VG }(m g / 100 m l) \\
\text { PVI }(\mu U / m l) \\
\text { PVG }(m \mu g / m l)\end{array}$ & $\begin{array}{l}104 \\
1.3\end{array}$ & $\begin{array}{l}69 \\
1.3\end{array}$ & $\begin{array}{l}91 \\
94 \\
1.3\end{array}$ & $\begin{array}{c}86 \\
372 \\
2.2\end{array}$ & $\begin{array}{c}92 \\
367 \\
2.2\end{array}$ & $\begin{array}{c}88 \\
402 \\
2.8\end{array}$ & $\begin{array}{r}95 \\
134 \\
2.2\end{array}$ \\
\hline $\mathrm{PZ4}$ & 100 & $\begin{array}{l}\text { VG } \\
\text { PVI } \\
\text { PVG }\end{array}$ & $\begin{array}{l}283 \\
\quad 1.44\end{array}$ & $\begin{array}{l}193 \\
1.48\end{array}$ & $\begin{array}{l}90 \\
159 \\
1.58\end{array}$ & $\begin{array}{c}92 \\
1,538 \\
3.4\end{array}$ & $\begin{array}{r}88 \\
1,637 \\
4.4\end{array}$ & $\begin{array}{c}103 \\
1,141 \\
3.4\end{array}$ & $\begin{array}{c}109 \\
1,290 \\
3.2\end{array}$ \\
\hline PZ5 & 100 & $\begin{array}{l}\text { VG } \\
\text { PVI } \\
\text { PVG }\end{array}$ & $\begin{array}{l}45 \\
1.02\end{array}$ & $\begin{array}{l}35 \\
1.02\end{array}$ & $\begin{array}{c}103 \\
50 \\
1.0\end{array}$ & $\begin{array}{l}105 \\
139 \\
1.28\end{array}$ & $\begin{array}{l}102 \\
432 \\
\quad 1.46\end{array}$ & $\begin{array}{c}98 \\
308 \\
1.46\end{array}$ & $\begin{array}{l}102 \\
109 \\
1.2\end{array}$ \\
\hline PZ9 & 100 & $\begin{array}{l}\text { AG }(m g / 100 m l) \\
\text { PVI } \\
\text { PVG }\end{array}$ & 114 & $\begin{array}{l}169 \\
1.28\end{array}$ & $\begin{array}{l}186 \\
139 \\
1.18\end{array}$ & $\begin{array}{c}189 \\
>2,480 \\
2.8\end{array}$ & $\begin{array}{l}200 \\
546 \\
4.2\end{array}$ & $\begin{array}{c}224 \\
92 \\
4.2\end{array}$ & $\begin{array}{l}232 \\
149 \\
3.8\end{array}$ \\
\hline PZ10 & 100 & $\begin{array}{l}\text { AG } \\
\text { PVI } \\
\text { PVG }\end{array}$ & 233 & $\begin{array}{c}184 \\
1.3\end{array}$ & $\begin{array}{l}147 \\
159 \\
\quad 1.49\end{array}$ & $\begin{array}{c}146 \\
>2,480 \\
2.6\end{array}$ & $\begin{array}{c}149 \\
2,133 \\
4.6\end{array}$ & $\begin{array}{l}174 \\
794 \\
3.0\end{array}$ & $\begin{array}{l}183 \\
546 \\
1.92\end{array}$ \\
\hline PZ11 & 100 & $\begin{array}{l}\text { AG } \\
\text { PVI } \\
\text { PVG }\end{array}$ & 30 & $\begin{array}{l}30 \\
1.06\end{array}$ & $\begin{array}{l}133 \\
30 \\
1.12\end{array}$ & $\begin{array}{l}142 \\
94 \\
1.78\end{array}$ & $\begin{array}{c}174 \\
74 \\
2.3\end{array}$ & $\begin{array}{c}225 \\
55 \\
3.0\end{array}$ & $\begin{array}{c}273 \\
32 \\
2.2\end{array}$ \\
\hline \multirow[t]{4}{*}{$\begin{array}{l}\text { Mean } \\
\text { SD }\end{array}$} & & VG & & & $\begin{array}{l}95 \\
\pm 7.2\end{array}$ & $\begin{array}{l}94 \\
9.7\end{array}$ & $\begin{array}{l}94 \\
7.2\end{array}$ & $\stackrel{96}{7.6}$ & $\begin{array}{l}102 \\
7.0\end{array}$ \\
\hline & & AG & & & $\begin{array}{c}155 \\
\pm 27.5\end{array}$ & $\begin{array}{l}159 \\
26.1\end{array}$ & $\begin{array}{l}174 \\
25.5\end{array}$ & $\begin{array}{l}208 \\
29.2\end{array}$ & $\begin{array}{l}229 \\
45.1\end{array}$ \\
\hline & & PVI & $\begin{array}{r}135 \\
\pm 107\end{array}$ & $\begin{array}{r}113 \\
77\end{array}$ & $\begin{array}{r}105 \\
56\end{array}$ & $\begin{array}{r}>1,184 \\
1,134\end{array}$ & $\begin{array}{l}865 \\
821\end{array}$ & $\begin{array}{l}465 \\
424\end{array}$ & $\begin{array}{l}377 \\
483\end{array}$ \\
\hline & & PVG & & $\begin{array}{r}1.24 \\
\pm 0.17\end{array}$ & $\begin{array}{l}1.28 \\
0.22\end{array}$ & $\begin{array}{l}2.34 \\
0.76\end{array}$ & $\begin{array}{l}3.19 \\
1.36\end{array}$ & $\begin{array}{l}2.98 \\
0.90\end{array}$ & $\begin{array}{l}2.42 \\
0.93\end{array}$ \\
\hline Mean & axımal & $\begin{array}{lr}\text { PVI } & 1,149 \pm \\
\text { PVG: } & 2.13 \pm\end{array}$ & $\begin{array}{ll}37 & \mathrm{p}< \\
4 & \mathrm{p}<0 .\end{array}$ & & & & & & \\
\hline
\end{tabular}

TABLE V

Effect of endoportal injection of inactive secretin $(1.7 \mu g)$ on AG and PVI

\begin{tabular}{|c|c|c|c|c|c|c|c|c|c|c|c|}
\hline \multirow[b]{2}{*}{ Dog } & & \multirow{2}{*}{$\begin{array}{c}\text { Minutes before } \\
\text { injection }\end{array}$} & \multicolumn{9}{|c|}{ Minutes after injection } \\
\hline & & & 1 & 3 & 6 & 10 & 15 & 20 & 30 & 45 & 60 \\
\hline 35 & $\begin{array}{l}\mathrm{AG}(m g / 100 m l) \\
\operatorname{PVI}(\mu U / m l)\end{array}$ & $\begin{array}{l}138 \\
362\end{array}$ & $\begin{array}{l}126 \\
392\end{array}$ & $\begin{array}{l}128 \\
252\end{array}$ & $\begin{array}{l}122 \\
193\end{array}$ & $\begin{array}{l}129 \\
169\end{array}$ & $\begin{array}{l}127 \\
159\end{array}$ & $\begin{array}{l}135 \\
243\end{array}$ & $\begin{array}{l}130 \\
262\end{array}$ & $\begin{array}{l}134 \\
348\end{array}$ & $\begin{array}{l}138 \\
282\end{array}$ \\
\hline
\end{tabular}

though only one experiment with each of these hormones was performed, it would appear that they do not resemble the gastrointestinal hormones with respect to their effect upon insulin release.

The endoportal injection of $1.7 \mu \mathrm{g}$ of the inactive secretin preparation failed to elicit the customary response in insulin secretion (Table V).

Epinephrine suppressibility of secretin-induced insulin release. Porte, Graber, Kuzuya, and Williams (26) have demonstrated that the stimulatory effect of intravenously administered glucose and of glucagon upon insulin secretion is inhibited by epinephrine. It seemed of interest, therefore, to evaluate the effect of epinephrine infusion on the stimulation of insulin secretion induced by secretin. During the infusion of epinephrine by peripheral 

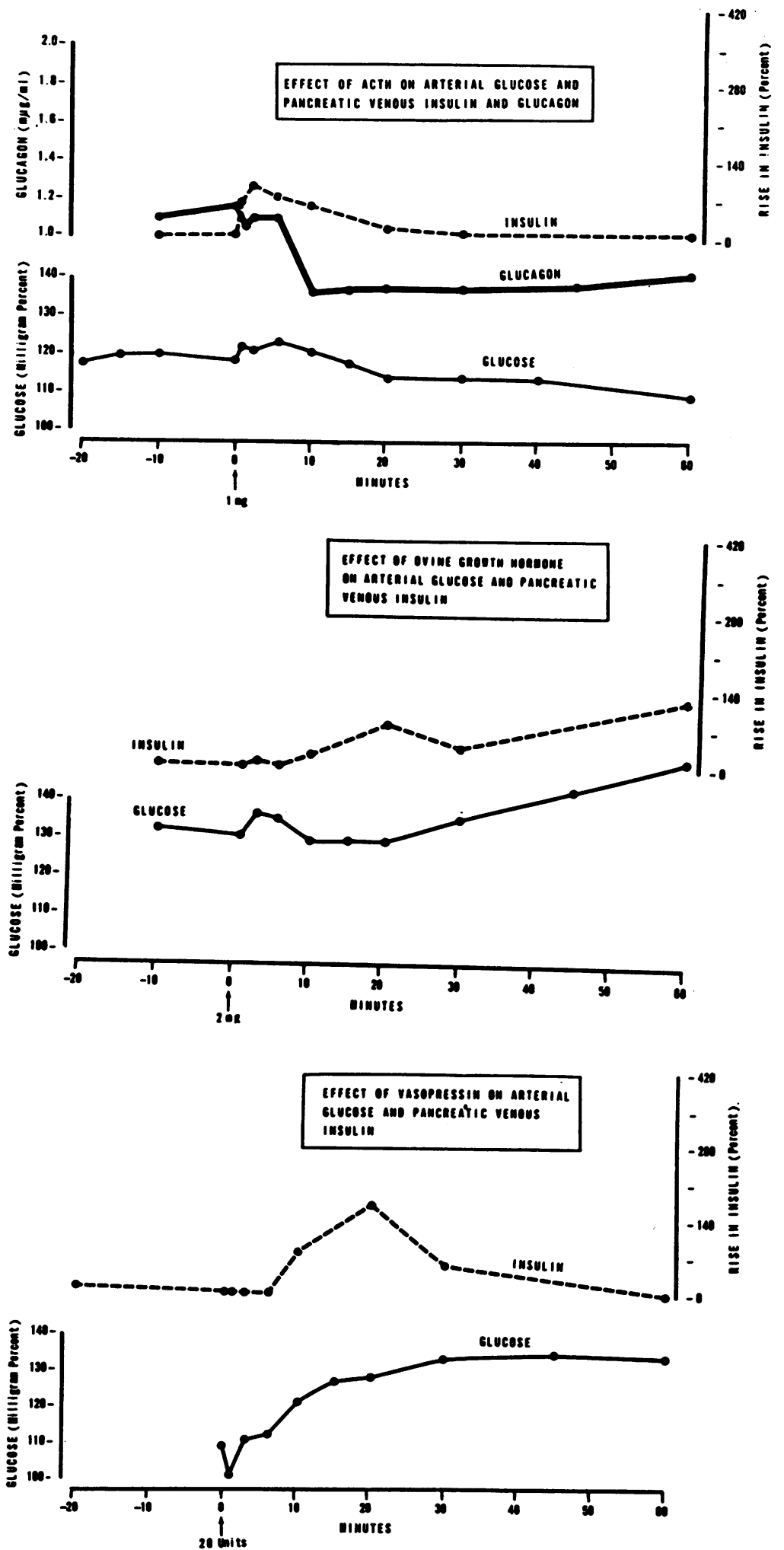

Fig. 4. EFFect of PERIPheral intravenous administration OF threE POLYPEPTIDE HORMONES NOT FOUND IN GASTROINTESTINAL TISSUES UPON THE PANCREATICODUODENAL VENOUS PLASMA LEVEL OF INSUliN AND ARTERIAI. PLASMA GLUCOSE LEVEL. 
Effect of epinephrine infusion on $A G$ and $P V I$ response to endoportal secretin and glucagon

\begin{tabular}{|c|c|c|c|c|c|c|c|c|c|c|c|c|c|c|c|c|c|c|c|c|}
\hline Dog & $\begin{array}{l}\text { Epi- } \\
\text { neph- } \\
\text { rine }\end{array}$ & & -10 & -0.5 & $\begin{array}{l}\text { Se- } \\
\text { cre- } \\
\text { tin }\end{array}$ & 1 & 3 & 6 & 10 & 15 & 20 & 30 & $\begin{array}{l}\text { Glu- } \\
\text { cagon }\end{array}$ & 1 & 3 & 6 & 10 & 15 & 20 & 30 \\
\hline & $\begin{array}{l}\mu g / \\
\min \end{array}$ & & & & $U$ & & & & & & & & $m_{\mu g}$ & & & & & & & \\
\hline \multirow[t]{2}{*}{113} & 2 & AG $(m g / 100 m l)$ & 252 & 255 & 30 & 252 & 258 & 246 & 243 & 252 & 255 & 258 & 680 & 252 & 285 & 279 & 294 & 282 & 276 & 270 \\
\hline & & PVI $(\mu U / m l)$ & 99 & 64 & & 179 & 60 & 45 & 35 & & 64 & 99 & & 139 & 129 & 144 & 109 & & 164 & 223 \\
\hline \multirow[t]{2}{*}{114} & 2 & AG & 231 & 243 & 30 & 246 & 246 & 252 & 255 & 255 & 258 & 255 & 700 & 258 & 270 & 270 & 258 & 252 & 258 & 246 \\
\hline & & PVI & 15 & 42 & & 69 & 94 & 74 & 89 & & 99 & 94 & & 89 & 55 & 40 & 60 & & 84 & 94 \\
\hline \multirow[t]{2}{*}{115} & 2 & AG & 236 & 232 & 30 & 220 & 226 & 226 & 224 & 222 & 216 & 228 & 720 & 238 & 250 & 256 & 254 & 250 & 250 & 244 \\
\hline & & PVI & 253 & 332 & & 223 & 114 & 149 & 228 & & 263 & 293 & & 303 & 308 & 312 & 317 & & 308 & 184 \\
\hline \multirow{2}{*}{\multicolumn{2}{|c|}{ Mean }} & AG & 240 & 243 & & 239 & 243 & 241 & 241 & 243 & 243 & 247 & & 249 & 268 & 268 & 269 & 261 & 261 & 253 \\
\hline & & PVI & 122 & 146 & & 157 & 89 & 89 & 117 & & 142 & 162 & & 177 & 164 & 165 & 162 & & 185 & 167 \\
\hline
\end{tabular}

vein at a rate of $2 \mu \mathrm{g}$ per minute, $30 \mathrm{U}$ of secretin was injected rapidly into the portal vein; $30 \mathrm{~min}$ utes later, $700 \mathrm{~m} \mu \mathrm{g}$ of glucagon was administered. As shown in Figure 5, no rise in mean pancreaticoduodenal insulin level was observed after either injection. The individual results of three such experiments are recorded in Table VI.

Effects of endoportal infusion of secretin. Although the sudden burst of insulin release that follows the injection of the enteric hormones is dramatic, it is extremely short-lived. Whereas the rise in insulin concentration observed in dogs after the endoportal injection of $1 \mu \mathrm{g}$ of glucagon lasted for 6 minutes or more (20), 6 minutes after the injection of secretin, pancreozymin, or gastrin, the insulin concentration in the pancreaticoduodenal vein was nearing its preinjection level. Even if one overestimates pancreatic blood flow

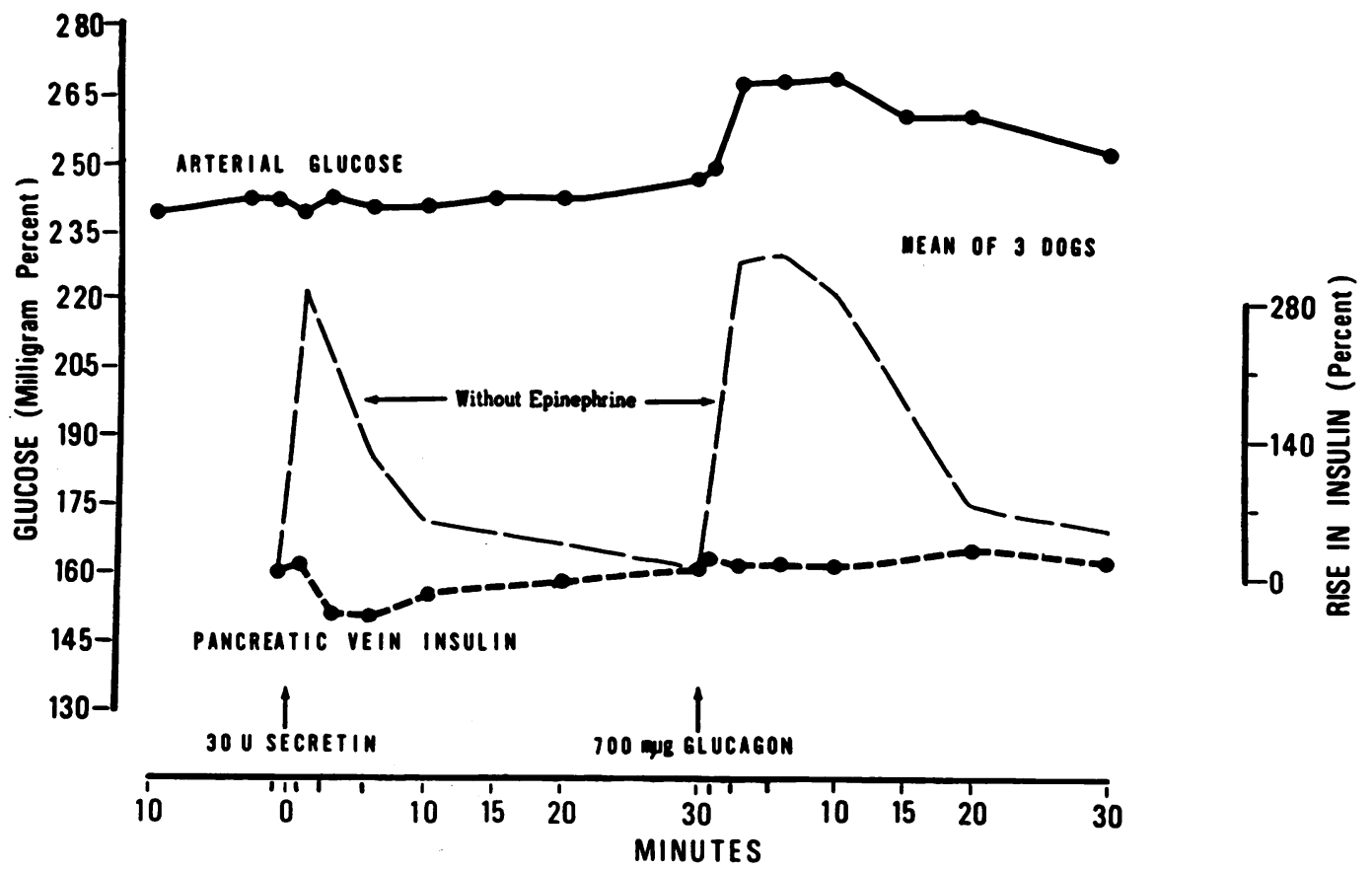

Fig. 5. EFFects OF THE RAPID ENDOPORTAL INJECTION OF SECRETIN AND GLUCAGON UPON PANCREATICODUODENAL VENOUS PLASMa LEVELS OF INSULIN DURING EPINEPHRINE INFUSion AT A RATE OF $2 \mu$ PER MINUTE. 


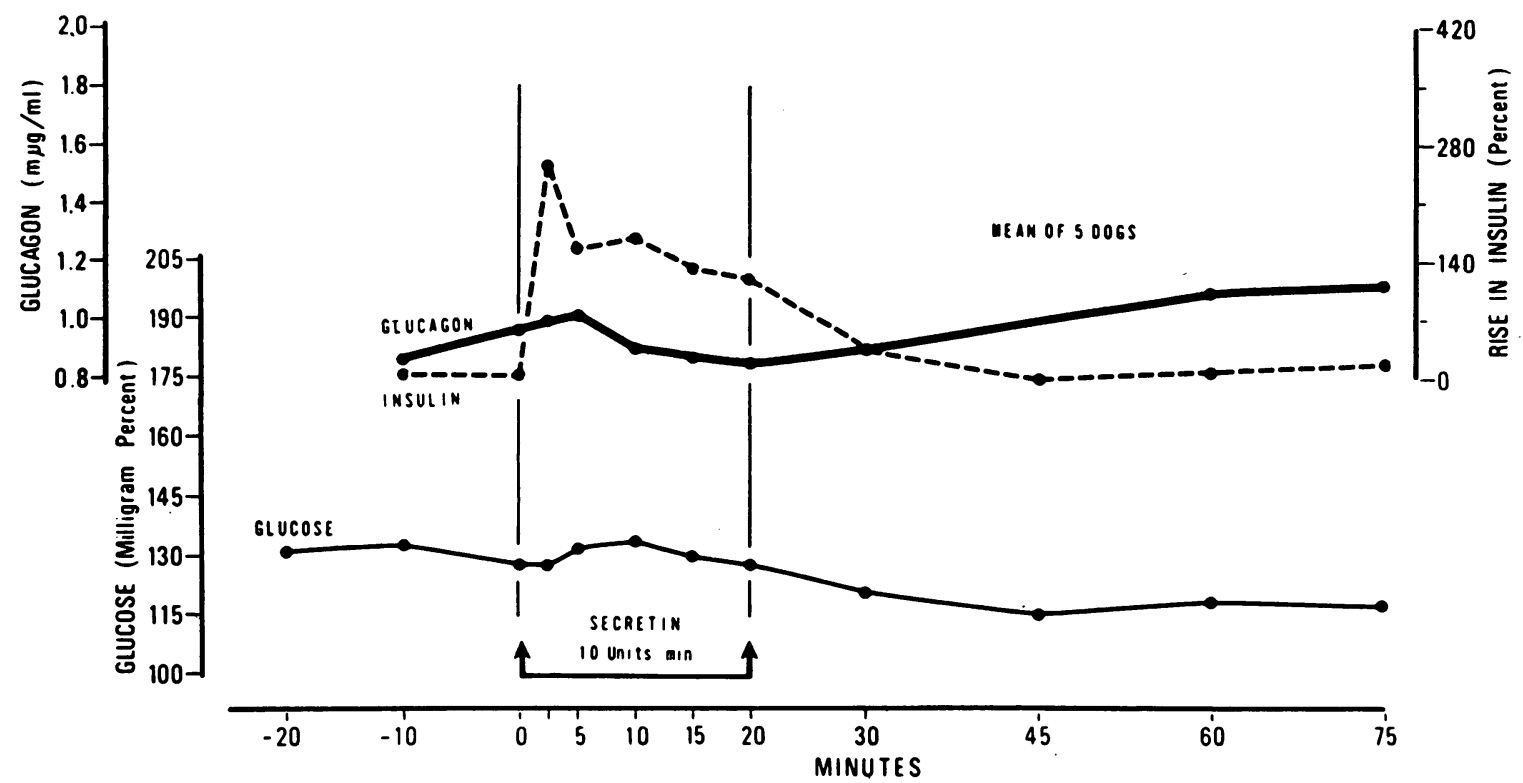

Fig. 6. EFFECT OF ENDOPORTAL INFUSION OF SECRETIN UPON PANCREATICODUODENAL VENOUS PLASMA LEVELS OF INSULIN and glucagon and arterial plasma glucose concentration.

to be $20 \mathrm{ml}$ per minute, the total increment in insulin output resulting from the endoportal injection of these three hormones in these experiments is not more than a few milliunits. Its physiologic importance can, therefore, be questioned.

To determine if sustained endoportal infusion of secretin would elicit a sustained increase in insulin secretion, we infused secretin at a rate of $10 \mathrm{U}$ per minute in a group of five dogs. The mean insulin level (Figure 6) rose initially from $173 \mu \mathrm{U}$ per $\mathrm{ml}(\mathrm{SD} \pm 91.7)$ to a peak at $2.5 \mathrm{~min}-$ utes of $604 \mu \mathrm{U}$ per $\mathrm{ml}(\mathrm{SD} \pm 406.8)$, an increase of $249 \%$, and declined to $435 \mu \mathrm{U}$ per $\mathrm{ml}$ ( $\mathrm{SD} \pm$ 417.3) 5 minutes after the start of the infusion. There appeared to be a slight downward trend in the mean pancreaticoduodenal insulin concentration throughout the remainder of the infusion, and its rate of decline accelerated only slightly when the infusion ended. The mean level of pancreaticoduodenal venous glucagon did not change significantly during the infusion, nor did the small rise in mean arterial glucose concentration appear to be significant. The individual results are recorded in Table VII.

If we assume the same overestimated value of $20 \mathrm{ml}$ per minute for pancreatic blood flow, it can be calculated that insulin secretion was augmented by approximately $105 \mathrm{mU}$ during the 20 -minute infusion of secretin, i.e., by $5.24 \mathrm{mU}$ per minute. Effects of endoportal infusion of pancreozymin. The effects upon insulin and glucagon secretion of pancreozymin infused endoportally at a rate of $30 \mathrm{U}$ per minute for 20 minutes were examined in a group of four dogs. The mean pancreaticoduodenal concentration of insulin rose rapidly from a preinjection level of $127 \mu \mathrm{U}$. per ml (SD \pm 17.4 ) to a peak of $1,191 \mu \mathrm{U}$ per $\mathrm{ml}(\mathrm{SD} \pm$ 319.3 ) at 10 minutes, a rise of more than $600 \%$ (Figure 7); during the last 10 minutes of the infusion, there was a decline to a mean level of $968 \mu \mathrm{U}$ per $\mathrm{ml}$, which was still more than six times the preinjection level. When the infusion was terminated, the insulin level fell to $372 \mu \mathrm{U}$ per $\mathrm{ml}(\mathrm{SD} \pm 164.8)$ within the first 10 minutes and reached the base-line value within 25 minutes after the end of the infusion. If we estimate a pancreatic blood flow of $20 \mathrm{ml}$ per minute, it can be calculated that a total of $346 \mathrm{mU}$ of insulin was added during the 20-minute infusion of pancreozymin, or about $17.3 \mathrm{mU}$ per minute. The changes in pancreatic venous insulin were reflected by appropriate, though smaller, alterations in arterial insulin concentration.

The mean glucagon level in pancreaticoduodenal 
TABLE VII

Effect of endoportal infusion of secretin (10 U/minute) on $A G, P V I$, and $P V G$

\begin{tabular}{|c|c|c|c|c|c|c|c|c|c|c|c|c|c|c|c|c|c|}
\hline \multirow[b]{2}{*}{ Dog } & \multirow[b]{2}{*}{ Dose } & & \multicolumn{3}{|c|}{$\begin{array}{c}\text { Minutes before } \\
\text { infusion }\end{array}$} & \multicolumn{5}{|c|}{ Infusion } & \multicolumn{7}{|c|}{ Minutes after infusion } \\
\hline & & & -20 & -10 & -0.5 & $2 \frac{1}{2}$ & 5 & 10 & 15 & 20 & 30 & 45 & 60 & 75 & 90 & 105 & 120 \\
\hline & $\boldsymbol{U}$ & & & & & & & & & & & & & & & & \\
\hline \multirow[t]{3}{*}{116} & 200 & $\mathrm{AG}(\mathrm{mg} / 100 \mathrm{ml})$ & 122 & 127 & 123 & 122 & 121 & 116 & 115 & 112 & 103 & 106 & 113 & 113 & 110 & & \\
\hline & & PVI $(\mu U / m l)$ & & 50 & 40 & 104 & 129 & 94 & 60 & 40 & 104 & 184 & 164 & 174 & 114 & & \\
\hline & & PVG $(m \mu g / m l)$ & & 0.7 & 0.78 & 0.82 & 0.96 & 0.56 & & 0.48 & 0.88 & & 0.90 & & 1.04 & & \\
\hline \multirow[t]{3}{*}{129} & 200 & AG & 137 & 137 & 132 & 133 & 133 & 129 & 126 & 125 & 118 & 118 & 133 & 133 & 136 & & \\
\hline & & PVI & & 104 & 164 & 794 & 382 & 164 & 193 & 114 & 84 & 134 & 253 & 303 & 317 & & \\
\hline & & PVG & & 0.82 & 1.04 & 0.88 & 0.90 & 0.96 & & 0.82 & 0.78 & & 0.98 & & 0.96 & & \\
\hline \multirow[t]{3}{*}{130} & 200 & AG & 124 & 124 & 122 & 120 & 120 & 123 & 130 & 139 & 141 & 136 & 148 & 143 & 136 & & \\
\hline & & PVI & & 84 & 114 & 238 & 99 & 35 & 55 & 60 & 50 & 84 & 179 & 213 & 179 & & \\
\hline & & PVG & & 0.94 & 1.00 & 0.92 & 1.0 & 1.0 & & 1.0 & 0.96 & & 1.02 & & 1.1 & & \\
\hline \multirow[t]{3}{*}{149} & 200 & AG & 133 & 132 & 134 & 137 & 155 & 169 & 156 & 143 & 130 & 110 & 100 & 98 & 102 & 103 & 104 \\
\hline & & PVI & & 253 & 248 & 1,240 & 1,240 & 1,488 & 1,290 & 1,290 & 794 & 367 & 179 & 179 & 149 & 129 & 144 \\
\hline & & PVG & & 0.7 & 0.8 & 1.14 & 1.26 & 1.04 & 1.04 & 0.94 & 0.88 & 1.02 & 1.1 & & 1.2 & 1.1 & 1.4 \\
\hline \multirow[t]{3}{*}{150} & 200 & AG & 144 & 138 & 130 & 126 & 130 & 132 & 126 & 121 & 112 & 106 & 103 & 105 & 108 & 110 & 108 \\
\hline & & PVI & & 258 & 298 & 645 & 327 & 546 & 397 & 402 & 124 & 129 & 179 & 174 & 144 & 184 & 144 \\
\hline & & PVG & & 1.12 & 1.18 & 1.2 & 1.0 & 0.96 & 0.96 & 1.0 & 1.02 & 1.08 & 1.44 & & 1.32 & 1.56 & 1.28 \\
\hline \multirow{5}{*}{$\begin{array}{l}\text { Mean } \\
\text { SD }\end{array}$} & & AG & 132 & 132 & 128 & 128 & 132 & 134 & 131 & 128 & 121 & 115 & 119 & 118 & 118 & & \\
\hline & & \pm & 8.1 & 5.5 & 4.8 & 5.8 & 12.6 & 18.4 & 13.6 & 11.5 & 13.4 & 11.3 & 18.4 & 17.0 & 14.6 & & \\
\hline & & PVI & & 150 & 173 & 604 & 435 & 465 & 399 & 381 & 231 & 180 & 191 & 209 & 181 & & \\
\hline & & \pm & & 88.8 & 91.7 & 406.8 & 417.3 & 541.8 & 462.5 & 472.8 & 282.6 & 98.2 & 30.4 & 47.7 & 70.2 & & \\
\hline & & $\begin{array}{l}\text { PVG } \\
\pm\end{array}$ & & $\begin{array}{l}0.86 \\
0.14\end{array}$ & $\begin{array}{l}0.96 \\
0.15\end{array}$ & $\begin{array}{l}0.99 \\
0.16\end{array}$ & $\begin{array}{l}1.02 \\
0.15\end{array}$ & $\begin{array}{l}0.90 \\
0.19\end{array}$ & & $\begin{array}{l}0.85 \\
0.19\end{array}$ & $\begin{array}{l}0.90 \\
0.12\end{array}$ & & $\begin{array}{l}1.09 \\
0.38\end{array}$ & & $\begin{array}{l}1.12 \\
0.16\end{array}$ & & \\
\hline
\end{tabular}

TABLE VIII

Effect of endoportal infusion of pancreozymin-cholecystokinin (30 U/minute) on $A G$, $P V I, P V G, A I$, and arterial glucagon $(A g)$

\begin{tabular}{|c|c|c|c|c|c|c|c|c|c|c|c|c|c|c|c|c|c|c|}
\hline \multirow[b]{2}{*}{ Dog } & \multirow[b]{2}{*}{ Dose } & & \multicolumn{3}{|c|}{$\begin{array}{c}\text { Minutes before } \\
\text { infusion }\end{array}$} & \multicolumn{5}{|c|}{ Infusion } & \multicolumn{8}{|c|}{ Minutes after infusion } \\
\hline & & & -20 & -10 & -0.5 & 1 & $2 \frac{1}{2}$ & 5 & 10 & 15 & 20 & 30 & 45 & 60 & 75 & 90 & 105 & 130 \\
\hline & $\boldsymbol{U}$ & & & & & & & & & & & & & & & & & \\
\hline \multirow[t]{5}{*}{131} & 600 & $\mathrm{AG}(\mathrm{mg} / 100 \mathrm{ml})$ & 125 & 126 & 124 & & 126 & 124 & 126 & 126 & 123 & 112 & 110 & 96 & 103 & 100 & & \\
\hline & & PVI $(\mu U / m l)$ & & 149 & 154 & & 694 & 1,042 & 1,389 & 893 & 546 & 169 & 144 & 99 & 144 & 139 & & \\
\hline & & AI $(\mu U / m l)$ & & 37 & 45 & & 181 & 119 & 206 & & 161 & 79 & & 57 & & & & - \\
\hline & & PVG $(m \mu g / m l)$ & & 2.6 & 2.2 & & 3.2 & 4.0 & 3.8 & & 3.4 & 2.6 & & 2.4 & & 3.2 & & \\
\hline & & $\mathrm{Ag}(m \mu g / m l)$ & & 0.8 & 0.8 & & 0.8 & 0.8 & 1.0 & & 1.0 & & & 0.8 & & & & \\
\hline \multirow[t]{5}{*}{132} & 600 & AG & 118 & 122 & 113 & & 119 & 142 & 209 & 235 & 238 & 239 & 215 & 159 & 130 & 111 & 93 & \\
\hline & & PVI & & 74 & 109 & & 644 & 596 & 644 & 694 & 596 & 253 & 144 & 184 & 119 & 84 & & \\
\hline & & AI & & 47 & 50 & & 141 & 246 & 335 & & 322 & 184 & & 50 & & & & \\
\hline & & PVG & & 0.84 & 0.92 & & 1.32 & 1.42 & 2.2 & & 2.0 & 1.44 & & 0.94 & & 0.82 & & \\
\hline & & Ag & & 0.8 & 0.6 & & 0.8 & 1.0 & 1.4 & & 1.2 & 1.0 & & 0.8 & & & & \\
\hline \multirow[t]{5}{*}{142} & 600 & AG & 124 & 124 & 121 & 124 & 122 & 136 & 178 & 202 & 208 & 189 & 144 & 114 & 103 & 103 & 100 & 103 \\
\hline & & PVI & & 179 & 139 & 124 & 892 & 1,140 & 1,440 & 1,400 & 1,440 & 546 & 283 & 129 & 114 & 129 & 124 & 99 \\
\hline & & AI & & 40 & 37 & & 87 & 273 & 546 & & 54 & 243 & & 47 & & & & \\
\hline & & PVG & & 0.62 & 0.6 & 0.54 & 1.04 & 1.5 & 1.56 & 1.8 & 1.78 & 0.96 & 0.84 & 0.78 & 0.74 & 0.86 & 0.96 & 0.78 \\
\hline & & Ag & & 0.6 & 0.6 & & 0.8 & 1.0 & 1.4 & & 1.6 & 1.0 & & 0.8 & & & & \\
\hline \multirow[t]{3}{*}{143} & 600 & AG & 137 & 138 & 135 & 139 & 140 & 159 & 215 & 246 & 263 & 236 & 164 & 108 & 91 & 95 & 103 & 110 \\
\hline & & PVI & & 104 & 104 & 243 & 794 & 1,042 & 1,290 & 1,339 & 1,290 & 521 & 208 & 89 & 79 & 94 & 89 & 89 \\
\hline & & PVG & & 0.52 & 0.72 & 0.66 & 1.02 & 1.7 & 1.66 & 1.72 & 1.72 & 0.84 & 0.66 & 0.64 & 0.62 & 0.62 & 0.6 & 0.62 \\
\hline Mean & & AG & 126 & 128 & 123 & & 127 & 140 & 182 & 202 & 208 & 194 & 158 & 119 & 107 & 102 & 99 & \\
\hline \multirow[t]{5}{*}{$\mathrm{SD}$} & & \pm & 6.9 & 6.2 & 11.1 & & 8.8 & 14.2 & 35.5 & 47.9 & 49.3 & 51.3 & 39.1 & 25.1 & 12.4 & 9.2 & & \\
\hline & & PVI & & 127 & 127 & & 756 & 955 & 1,191 & 1,092 & 968 & 372 & 195 & 125 & 114 & 112 & & \\
\hline & & \pm & & 38.8 & 17.4 & & 95.3 & 211.1 & 319.3 & 306.5 & 400.8 & 164.8 & 56.4 & 37.8 & 22.4 & 23.0 & & \\
\hline & & PVG & & 1.15 & 1.11 & & 1.64 & 2.16 & 2.31 & & 2.23 & 1.46 & & 1.19 & & 1.38 & & \\
\hline & & \pm & & 0.84 & 0.64 & & 0.91 & 1.05 & 0.88 & & 0.67 & 0.69 & & 0.71 & & 1.05 & & \\
\hline
\end{tabular}




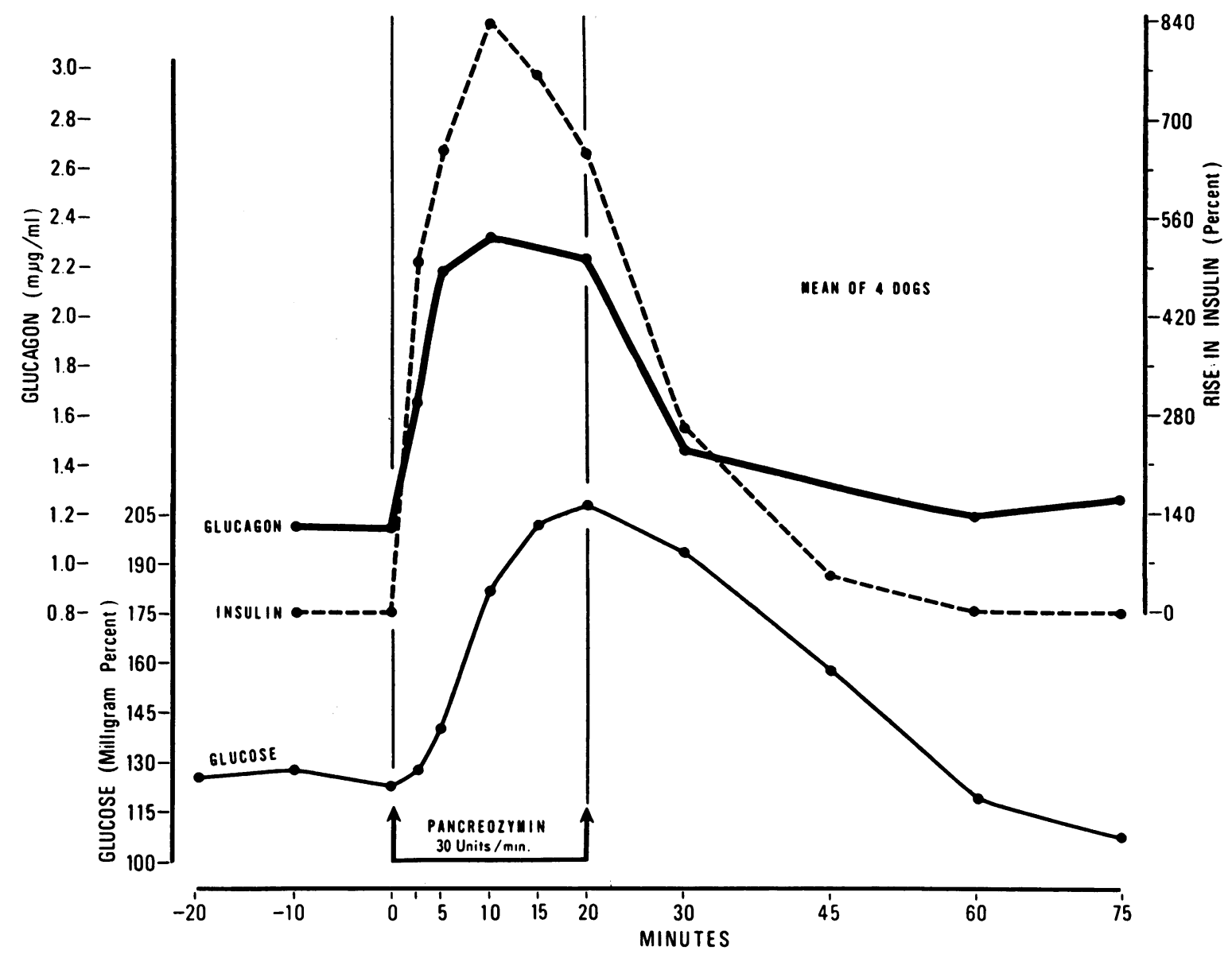

Fig. 7. EFFECT OF ENDOPORTAL INFUSION OF PANCREOZYMIN UPON PANCREATICODUODENAL VENOUS PLASMA LEVELS OF INSULIN AND GLUCAGON AND ARTERIAL PLASMA LEVELS OF GLUCOSE.

venous plasma also rose promptly after the start of the infusion from a preinjection level of 1.11 $\mathrm{m} \mu \mathrm{g}$ per $\mathrm{ml}(\mathrm{SD} \pm 0.64)$ to $2.16 \mathrm{~m} \mu \mathrm{g}$ per $\mathrm{ml}$ $(\mathrm{SD} \pm 1.05)$ at 5 minutes and remained at or above this level until the termination of the infusion, at which point it declined rapidly to a level of $1.46 \mathrm{~m} \mu \mathrm{g}$ per $\mathrm{ml} 10$ minutes after termination. If we assume a pancreatic blood flow of $20 \mathrm{ml}$ per minute, glucagon secretion was augmented by approximately $408 \mathrm{~m} \mu \mathrm{g}$ or $20.4 \mathrm{~m} \mu \mathrm{g}$ per minute during the infusion. The changes in pancreatic venous glucagon were reflected by small changes in arterial glucagon levels.

The mean arterial plasma glucose level rose from a preinjection level of $123 \mathrm{mg}$ per $100 \mathrm{ml}$ $(\mathrm{SD} \pm 11.1)$ to $140 \mathrm{mg}$ per $100 \mathrm{ml}(\mathrm{SD} \pm 14.2)$ during the first 5 minutes of the infusion. During the second 10 minutes, however, it ascended more rapidly to a level of $182 \mathrm{mg}$ per $100 \mathrm{ml}$ (SD \pm $35.5)$ at 10 minutes and reached a peak level of $208 \mathrm{mg}$ per $100 \mathrm{ml}(\mathrm{SD} \pm 49.3)$ at the end of the infusion. Upon termination of the infusion, the mean plasma glucose concentration declined at a gradual rate of $2.2 \mathrm{mg}$ per minute and required more than 30 minutes to reach the preinjection level. The individual results of all experiments are recorded in Table VIII.

\section{Discussion}

These results provide evidence of a relationship between the hormones of the gastrointestinal tract and those of the islets of Langerhans. They thus support the 60-year-old concept that secretin is biologically capable of augmenting insulin secretion. These studies also reveal, however, that 
TABLE IX

Effects of gastrointestinal hormones and pancreatic glucagon

\begin{tabular}{cccc}
\hline \hline Hormone & \multicolumn{1}{c}{ Arterial glucose } & Insulin secretion & Glucagon secretion \\
\hline Glucagon, $1 \mu \mathrm{g}$ & $\begin{array}{c}\text { Prompt } 50 \mathrm{mg} / 100 \mathrm{ml} \text { rise; } \\
\text { peak at } 6 \mathrm{minutes.}\end{array}$ & $\begin{array}{c}\text { Prompt } 250 \% \text { rise; } \\
\text { peak at } 6 \text { minutes }\end{array}$ & \\
$\begin{array}{c}\text { Secretin, } 20-30 \mathrm{U} \\
(1-2 \mu \mathrm{g})\end{array}$ & No effect & $\begin{array}{c}\text { Vertical } 290 \% \text { rise; } \\
\text { peak at } 1 \text { minute. }\end{array}$ & None \\
$\begin{array}{c}\text { Gastrin, } 0.13-0.2 \mathrm{U} \\
(30-34 \mathrm{mg})\end{array}$ & No effect & $\begin{array}{c}\text { Vertical } 390 \% \text { rise; } \\
\text { peak at } 1 \text { minute. }\end{array}$ & None, or very slight. \\
$\begin{array}{c}\text { Pancreozymin- } \\
\text { cholecystokinin, } \\
100 \mathrm{U}(17 \mu \mathrm{g})\end{array}$ & Late rise; peak at 10 minutes. & $\begin{array}{c}\text { Vertical } 480 \% \text { rise; } \\
\text { peak at } 1 \text { minute. }\end{array}$ & $\begin{array}{c}\text { Prompt } 80 \% \text { rise; } \\
\text { peak at 3 minutes. }\end{array}$ \\
\hline
\end{tabular}

secretin is but one of several beta-cytotropic hormones present in the gastrointestinal tract. The observations of Meade (30) and the results of the present study reveal a brisk release of insulin after the rapid injection and the continuous infusion of the highly purified pancreozymin preparation of Jorpes and Mutt. In addition, both crude gastrincontaining antral extract and purified porcine gastrin II exhibited insulin-releasing activity similar in pattern to that of secretin and pancreozymin. Although the doses employed were large, particularly in the case of pancreozymin, Meade (30) has noted a similar response in portal venous insulin concentration after the rapid administration of 6 to $7.5 \mathrm{U}$ of pancreozymin by peripheral vein. Glucagon has recently been shown to have potent insulin-releasing activity by Samols, Tyler, Megyesi, and Marks (19) and by Crockford, Porte, Wood, and Williams (27) in man, and by Ketterer, Eisentraut, and Unger (20) in dogs. In the latter study, the pattern of the response of pancreaticoduodenal insulin concentration and of arterial plasma glucose concentration to the rapid endoportal injection of $1 \mu \mathrm{g}$ of glucagon was distinctly different from the response to the three hormones studied here; after glucagon injection, the mean insulin and glucose levels rose concomitantly to a plateau peak at 3 to 6 minutes after injection and remained above the preinjection level for almost 20 minutes. The patterns of response for each of the four beta-cytotropic hormones are compared in Table IX.

The ubiquity of "glucagon-like" biologic activity $(31,32)$ and immunoreactivity $(19,28,29)$ raises the possibility of its presence as a contaminant in other hormone preparations of the gut.
Furthermore, there appears to be a structural similarity between glucagon, composed of 29 amino acids (33), and secretin, composed of 27 (34), that has led to the suggestion of an overlap in their biologic properties (35). The crude gastrin preparation employed here contained from 17 to 38 $\mathrm{m} \mu \mathrm{g}$ of glucagon-like immunoreactivity per milligram, but since glucagon-free gastrin II caused a similar response, it seems unlikely that glucagon was an important factor in the observed response. Pancreozymin contained only 0.02 to $0.06 \mathrm{~m} \mu \mathrm{g}$ per $U$ of glucagon-like immunoreactivity, not enough to have played a significant role in the genesis of the insulin response. Finally, glucagon-like immunoreactivity of the secretin preparation ranged from 0 to $3.9 \mathrm{~m} \mu \mathrm{g}$, not nearly enough to stimulate insulin secretion to the degree observed. (Despite a possible structural similarity of the glucagon and secretin molecules, the absence of hyperglycemia after the endoportal injection of large doses of secretin and the immunologic displacement by $20 \mu \mathrm{g}$ of secretin of the equivalent of only $0.0009 \mu \mathrm{g}$ of glucagon reveal major biologic and immunologic differences.)

It would appear that the pattern of insulin release induced by gastrin, secretin, and pancreozymin is a characteristic of these gastrointestinal hormones and is not shared by any of the nongastrointestinal polypeptides studied. The insulinogenic effect of ACTH, previously reported in vitro by Sussman, Vaughn, and Timmer (36), differed both in timing and magnitude.)

In these experiments, pancreozymin had a direct glucagon-releasing effect and is consequently the first hormone thus far shown to have this property. Although the pancreozymin prepara- 
tion did contain traces of glucagon, the quantities were far too low to account for a rise in pancreatic venous glucagon of the magnitude and duration observed. The relative timing of the arterial hyperglycemia and the hyperglucagonemia suggests that the former could be a consequence of the release of endogenous glucagon rather than of a glycogenolytic effect of the pancreozymin itself. The occurrence of hyperglycemia in the retrograde catheterization experiments does not weigh against this possibility, since venous channels other than the pancreaticoduodenal vein drain the endocrine pancreas and arterial glucagon levels rose in those experiments.

The metabolic importance of the quantities of insulin released in response to the enteric hormones is not apparent from these data, since, surprisingly, glucose did not decline significantly and free fatty acid levels were not measured. However, Meade has observed a fall in FFA concentration after the administration by peripheral vein of much smaller doses of pancreozymin to dogs $(30)$.

Proof of the physiologic significance of the enteric hormones in the control of islet hormone secretion will require demonstration that similar responses in islet hormone secretion are provoked by maneuvers that cause the secretion of endogenous enteric hormones. Thus far, reported attempts to enhance insulin secretion by intraduodenal instillation of acid, a stimulus for secretin secretion have been unsuccessful (37). On the other hand, the intraduodenal instillation of protein hydrolyzates has been shown to cause a striking rise in both insulin and glucagon secretion (38). Pancreozymin, which is secreted in response to amino acid ingestion (39) and which duplicates qualitatively the effects of amino acids upon islet hormone secretion, could be that hormone.

The fact that four hormones of the gastrointestinal tract, gastrin, secretin, pancreozymin-cholecystokinin, and "glucagon" of intestinal origin (40), all have insulin-releasing activity suggests a chain of beta-cytotropic hormones extending from the antrum to the ileum. Early augmentation of insulin secretion by these hormones to a degree appropriate to the quantity and type of nutrients ingested before the attainment of peak blood levels of substrates would permit prompt substrate disposal without excessive hypergly- cemia or hyperaminoacidemia, which would occur after large meals if insulin release were entirely dependent upon arterial substrate concentration.

\section{References}

1. Moore, B., E. S. Edie, and J. H. Abram. On the treatment of diabetes mellitus by acid extract of duodenal mucous membrane. Biochem. J. 1906, $1,28$.

2. Dixon, W. E., and J. H. Wadia. The action of intestinal extracts. Brit. med. J. 1926, 1, 820.

3. Zunz, E., and J. La Barre. Hyperinsulinémie consécutive à l'injection de solution de sécretine non hypotensive. C. R. Soc. Biol. (Paris) 1928, 98, 1435.

4. Heller, H. Über den Blutzuckerwirksamen Stoff in Sekretinextrakten. Naunyn-Schmiedeberg's Arch. exp. Path. Pharmak. 1929, 145, 343.

5. Laughton, N. B., and A. B. Macallum. The relation of duodenal mucosa to the internal secretion of the pancreas. Proc. roy. Soc. B. 1932, 111, 37.

6. Heller, H. Über das Insulotrope Hormon der Darmschleimhaut (duodenin). Naunyn-Schmiedeberg's Arch. exp. Path. Pharmak. 1935, 177, 127.

7. LaBarre, J. Sur les possibilités d'un traitement du diabète par l'incrétine. Bull. Acad. roy. Méd. Belg. 1932, 12, 620.

8. Loew, E. R., J. S. Gray, and A. C. Ivy. Is a duodenal hormone involved in carbohydrate metabolism? Amer. J. Physiol. 1940, 129, 659.

9. Dupré, J. An intestinal hormone affecting glucose disposal in man. Lancet 1964, 2, 672.

10. Crick, J., A. A. Harper, and H. S. Raper. On the preparation of secretin and pancreozymin. J. Physiol. (Lond.) 1949, 110, 367.

11. Dupré, J., and J. C. Beck. Stimulation of release of insulin by an extract of intestinal mucosa. Diabetes 1966, 15, 555.

12. Pfeiffer, E. F., M. Telib, J. Ammon, F. Melani, and H. Ditschuneit. Letter to the editor. Diabetologia 1965, 1, 131.

13. McIntyre, N., D. S. Turner, and C. D. Holdsworth. Intestinal factors and insulin secretion (abstract). Diabetologia 1965, 1, 73.

14. Unger, R. H., H. Ketterer, A. Eisentraut, and J. Dupré. Effect of secretin on insulin secretion. Lancet 1966, 2, 24.

15. Dupré, J., L. Rojas, J. J. White, R. H. Unger, and J. C. Beck. Effects of secretin on insulin and glucagon in portal and peripheral blood in man. Lancet 1966, 2, 26.

16. Hoffman, W. S. Rapid photoelectric method for the determination of glucose in blood and urine. $\mathrm{J}$. biol. Chem. 1937, 120, 51.

17. Yalow, R. S., and S. A. Berson. Immunoassay of endogenous plasma insulin in man. J. clin. Invest. 1960, 39, 1157. 
18. Unger, R. H., A. M. Eisentraut, M. S. McCall, and L. L. Madison. Glucagon antibodies and an immunoassay for glucagon. J. clin. Invest. 1961, 40, 1280.

19. Samols, E., J. Tyler, C. Megyesi, and V. Marks. Immunochemical glucagon in human pancreas, gut, and plasma. Lancet 1966, 2, 727.

20. Ketterer, H., A. M. Eisentraut, and R. H. Unger. The effect upon insulin secretion of physiologic doses of glucagon administered via the portal vein. Diabetes, in press.

21. Eisentraut, A., N. Whissen, and R. H. Unger. Incubation damage in the radioimmunoassay for human plasma glucagon and its prevention with "Trasylol." Submitted for publication.

22. Jorpes, J. E., and V. Mutt. Personal communication.

23. Tauber, S., and L. L. Madison. The isolation and characterization of porcine gastrin. J. biol. Chem. 1965, 240, 645 .

24. Gregory, R. A., and H. J. Tracy. The constitution and properties of 2 gastrins extracted from hog antral mucosa. Gut 1964, 5, 103.

25. Samols, E., G. Marri, and V. Marks. Promotion of insulin secretion by glucagon. Lancet 1965, 2, 415.

26. Porte, D., Jr., A. L. Graber, T. Kuzuya, and R. H. Williams. The effect of epinephrine on immunoreactive insulin levels in man. J. clin. Invest. 1966, 45, 228.

27. Crockford, P. M., D. Porte, Jr., F. C. Wood, Jr., and R. H. Williams. Effect of glucagon on serum insulin, plasma glucose and free fatty acids in man. Metabolism 1966, 15, 114.

28. Unger, R. H., A. Eisentraut, K. Sims, M. S. McCall, and L. L. Madison. Sites of origin of glucagon in dogs and humans (abstract). Clin. Res. 1961, 9, 53.

29. Unger, R. H., H. Ketterer, and A. M. Eisentraut. Distribution of immunoassayable glucagon in gastrointestinal tissues. Metabolism 1966, 15, 865.
30. Meade, R. C., H. A. Kneubuhler, W. J. Schulte, and J. J. Barboriak. Stimulation of insulin secretion by pancreozymin. Diabetes, in press.

31. Sutherland, E. W., and C. de Duve. Origin and distribution of the hyperglycemic-glycogenolytic factor of the pancreas. J. biol. Chem. 1948, 175, 663.

32. Makman, M. H., and E. W. Sutherland. Use of liver adenyl cyclase for assay of glucagon in human gastro-intestinal tract and pancreas. Endocrinology 1964, 75, 127.

33. Bromer, W. W., L. G. Sinn, A. Staub, and O. K. Behrens. The amino acid sequence of glucagon. J. Amer. chem. Soc. 1956, 78, 3858.

34. Mutt, V., and J. E. Jorpes. Secretin: isolation and determination of structure (abstract). Proceedings of the Fourth International Symposium on the Chemistry of Natural Products. Stockholm, Sweden, June 26, 1966.

35. Mutt, V., and J. E. Jorpes. Contemporary developments in the biochemistry of the gastrointestinal hormones. Recent Progr. Hormone Res. 1967, 23, in press.

36. Sussman, K. E., G. D. Vaughn, and R. F. Timmer. Factors controlling insulin secretion from the perfused isolated rat pancreas (abstract). Diabetes 1966, 15, 521.

37. Boyns, D. R., R. J. Jarrett, and H. Keen. Intestinal hormones and plasma-insulin. Lancet 1966, 1, 409.

38. Ohneda, A., H. Ketterer, A. M. Eisentraut, and R. H. Unger. Effect of glucose and of amino acids on glucagon secretion (abstract). Clin. Res. 1967, 15, 62.

39. Wang, C. C., and M. I. Grossman. Physiological determination of release of secretin and pancreozymin from intestine of dogs with transplanted pancreas. Amer. J. Physiol. 1951, 164, 527.

40. Hanson, J., A. Ohneda, A. Eisentraut, and R. H. Unger. Characterization of gut "glucagon" (abstract). Clin. Res. 1967, 15, 43. 